\title{
Review
}

\section{Pulmonary delivery of nanoparticle chemotherapy for the treatment of lung cancers: challenges and opportunities}

\author{
Sharad MANGAL, Wei GAO, Tonglei LI, Qi (Tony) ZHOU* \\ Department of Industrial and Physical Pharmacy, College of Pharmacy, Purdue University, West Lafayette, IN 47907-2091, USA
}

\begin{abstract}
Lung cancer is the second most prevalent and the deadliest among all cancer types. Chemotherapy is recommended for lung cancers to control tumor growth and to prolong patient survival. Systemic chemotherapy typically has very limited efficacy as well as severe systemic adverse effects, which are often attributed to the distribution of anticancer drugs to non-targeted sites. In contrast, inhalation routes permit the delivery of drugs directly to the lungs providing high local concentrations that may enhance the antitumor effect while alleviating systemic adverse effects. Preliminary studies in animals and humans have suggested that most inhaled chemotherapies are tolerable with manageable pulmonary adverse effects, including cough and bronchospasm. Promoting the deposition of anticancer drugs in tumorous cells and minimizing access to healthy lung cells can further augment the efficacy and reduce the risk of local toxicities caused by inhaled chemotherapy. Sustained release and tumor localization characteristics make nanoparticle formulations a promising candidate for the inhaled delivery of chemotherapeutic agents against lung cancers. However, the physiology of respiratory tracts and lung clearance mechanisms present key barriers for the effective deposition and retention of inhaled nanoparticle formulations in the lungs. Recent research has focused on the development of novel formulations to maximize lung deposition and to minimize pulmonary clearance of inhaled nanoparticles. This article systematically reviews the challenges and opportunities for the pulmonary delivery of nanoparticle formulations for the treatment of lung cancers.
\end{abstract}

Keywords:

Acta Pharmacologica Sinica (2017) 38: 782-797; doi: 10.1038/aps.2017.34; published online 1 May 2017

\section{Introduction}

Lung cancer is the second most common cancer worldwide, representing $\sim 14 \%$ of newly reported cases. The majority $(85 \%)$ of lung cancer cases is classified as non-small cell lung cancer (NSCLC), with the remaining classified as small cell lung cancer (SCLS) ${ }^{[1]}$. The American Cancer Society estimates that there were more than 200000 new cases of lung cancer and approximately 150000 deaths in 2017 in the United States alone, making it the deadliest among all types of cancer ${ }^{[2]}$.

Unfortunately, an early diagnosis of lung cancer is challenging, and at the time a diagnosis most lung cancers are in advanced metastatic stage. The metastatic spread of cancer to distant organs is the dominant reason for the dismal survival rate of advanced-stage lung cancer patients, with a 5-year survival rate of only $10 \%{ }^{[3-9]}$. The most common metastatic locations for lung cancer are typically the nervous system, bone,

\footnotetext{
${ }^{*}$ To whom correspondence should be addressed.

E-mail tonyzhou@purdue.edu

Received 2016-12-10 Accepted 2017-02-04
}

liver, respiratory system, and adrenal glands ${ }^{[10]}$.

Surgical removal/resection is the main treatment for nonmetastatic lung cancers. However, this technique can only be used in $10 \%-20 \%$ of patients with NSCLC and is limited by the number and the site of the lesions and the patient's respiratory and/or general status ${ }^{[1,12]}$. Lung cancers for which surgery is not a feasible option generally require chemotherapy to prolong survival, control symptoms and improve the quality of life of patients ${ }^{[13-16]}$.

Anticancer drugs must penetrate cancer tissues to attain a concentration necessary to exert effective tumor killing; indeed, suboptimal drug concentrations typically exhibit weak anti-tumor activity and additional concerns regarding drug resistance ${ }^{[17,18]}$. Intravenous administration inevitably causes a considerable proportion of chemotherapeutics to be widely distributed in various organs, leading to substantially low drug concentrations at tumorous sites. This necessitates the administration of high doses to attain therapeutically effective drug concentrations at the diseased sites. Such high doses can cause severe adverse effects, especially at the sites of rapidly 
dividing cells such as hair, skin, spleen and liver, among others $^{[18-20]}$. These toxicity concerns compromise the efficacy and compliance of systemic chemotherapy against lung cancer ${ }^{[21-24]}$. Furthermore, lung cancer sub-types may also be genetically diverse, making treatment even more difficult. Thus, there is an urgent need for new treatments with improved safety and efficacy.

\section{Inhaled chemotherapy}

Localized chemotherapy refers to the delivery of anticancer drugs directly to the affected organs, which can ensure higher concentrations in tumors compared to other non-target sites. Localized chemotherapy has been confirmed to be effective against various types of cancers, including ovarian and colorectal cancers ${ }^{[25-30]}$. Inhaled drug delivery facilitates the localized delivery of drugs directly to the lungs via the oral or nasal inhalation route. Inhalation is a non-invasive route of administration, and some inhaled dosage forms are easy to carry and use, making it a promising alternative to the parenteral routes of drug delivery for treating respiratory diseases. Inhalation therapies have been shown to be effective and are well accepted for the treatment of respiratory tract diseases such as asthma, chronic obstructive pulmonary disease (COPD) and respiratory tract infections.

Inhaled chemotherapy has been shown to be promising against lung cancers (Table 1$)^{[31-36]}$. Inhalation can alter the bio-distribution of drugs and promote the accumulation of a larger fraction in the lungs compared to parenteral administration $^{[37-41]}$. Furthermore, inhalation limits the systemic distribution of anticancer drugs and thus the associated toxicity ${ }^{[35,36]}$. Most adverse effects associated with inhaled chemotherapy were shown to be localized, including cough and glottitis, which are common and treatable. In some cases, respirationrelated complications, such as a drop in forced expiratory volume and hypoxia, have been reported. Most local adverse effects following inhaled chemotherapy have also been shown to be drug-, dose- and time-dependent ${ }^{[31-36,42-44]}$. However, it is not clear whether these adverse events were associated with disease progression or inhaled chemotherapy ${ }^{[34,35]}$.

A high proportion of inhaled drug has commonly been detected in the lymph nodes ${ }^{[32]}$. Inhaled drugs can also be deposited in the lymphatic tissue via the lymphatic circulation $^{[32]}$. Thus, inhaled chemotherapy may also be beneficial for the treatment of lung cancer that has metastasized to the lymph nodes ${ }^{[32]}$. Moreover, drugs that are absorbed into the lymphatic circulation can redistribute in peripheral airways, allowing access to otherwise poorly accessible areas of the lungs ${ }^{[42,45]}$. Thus, inhaled chemotherapy may be extremely beneficial in cases of cancer that has metastasized to the lung, which are usually located away from the major airways but receive blood from the pulmonary arteries and veins ${ }^{[46-48]}$. Aerosolized delivery of liposomal interleukin-2 (IL-2) in dogs has been shown to be effective against pulmonary metastases from osteosarcoma ${ }^{[49]}$. A combination of intravenously injected human natural killer cells and inhaled interleukin-2 had a synergic effect and increased the survival of mice with osteosarcoma lung metastases ${ }^{[50]}$. Inhaled chemotherapy has also been used as an adjuvant with systemic chemotherapy; however, no improvement in tumor efficacy was observed compared to systemic chemotherapy alone ${ }^{[33]}$.

Most lung cancers are in the metastatic stage at the time of diagnosis, and the treatment of lung cancer that has metastasized to other organs may further improve the efficacy of chemotherapy. There has been increasing interest in exploring the inhalation route for systemic drug delivery, such as insulin for diabetes or gene therapy ${ }^{[51,52]}$. Thus, it is possible that delivery via inhalation may be used to deliver chemotherapeutic agents systemically and target lung cancer metastasis to other organs. However, the effect of inhaled chemotherapy on metastasized lung cancer has not been investigated.

Although inhaled delivery has a clear pharmacokinetic advantage over systemic delivery, ensuring the deposition of the drug in the resident tumor is key to achieving efficient anti-tumor activity. However, the efficacy of inhaled chemotherapy depends on multiple factors, including tumor size, disease stage, drug penetration at the tumor site, physicochemical properties of drugs, local adverse effects, and patient condition. These factors play a dominant role in determining whether inhaled delivery is indeed a feasible and/or effective option for lung cancer therapy.

Respiratory tract obstruction due to lung cancer and other obstructive respiratory conditions such as cystic fibrosis and bronchiectasis can affect the deposition and distribution patterns of aerosols in the lungs. For example, a lung tumor can physically occlude the respiratory tract by reducing the crosssectional area of the lung, which can divert the airflow to nonoccluded areas and reduce the deposition of inhaled drugs to the tumor. The effects of tumors in terms of size and location on airflow, particle transport, and deposition patterns have been modeled ${ }^{[53]}$. It was shown that the particle deposition at tumor sites increases until the tumor blocks approximately half of the airway lumen and then decreases with further obstruction. It has also been proposed that the majority of the inhaled drug is deposited on the frontal surface of the tumor $^{[53]}$.

Despite the direct access to the lung tumor via inhalation, enhancing drug penetration to the lung tumor is also critical for achieving efficient anti-tumor activity. The depth of tumor penetration following topical deposition is usually limited and also depends on the physico-chemical properties of drugs, including the molecular weight, solubility, and apoptotic $\operatorname{activity}^{[17,42,54-58]}$. Furthermore, penetration of the drug to the tumor depends on the nature of the tumor, including the size, cellularity of the tumor and density of the interstitium ${ }^{[59]}$. It has been demonstrated that small nodules respond better to inhaled chemotherapy than larger nodules ${ }^{[40]}$. Thus, limited penetration and an inability to achieve an adequate drug concentration in the tumor tissue may limit the effectiveness of inhaled chemotherapy.

The uptake and direct toxicity of inhaled chemotherapy to healthy lung cells are relatively unknown. The deposition of high concentrations of anticancer drugs in healthy lung cells 
Table 1. Clinical studies investigating the safety and efficacy of inhaled chemotherapy.

$\begin{array}{ll}\text { Drugs } & \text { Outcomes }\end{array}$

Inhaled 5-Fluorouracil (5-FU)

Inhaled 5-FU

Inhaled doxorubicin with intravenous docetaxel and cisplatin

Inhaled doxorubicin as a solution at doses ranging from 0.4 to $9.4 \mathrm{mg} / \mathrm{m}^{2}$

Inhaled carboplatin with or without intravenous carboplatin

Inhaled gemcitabine (GCB) in a dose escalation study
Out of 6 patients receiving inhaled 5-FU, 4 showed an anticancer response, with 2 complete responders and 2 partial responders.

Safety

There were no side effects in the bronchial tree and pulmonary parenchyma but some patients showed glottitis. A very small fraction of 5-FU was detected in the systemic circulation ${ }^{[31]}$.

A satisfactory anti-tumor response was observed in 6 out of 10 patients who received inhaled 5-FU, with 2 complete responders, 4 partial responders and 4 with no response. A high concentration (5-15 times higher) of drug was detected in tumor tissue compared with surrounding normal tissues within the lungs. High levels of 5-FU were detected in regional lymph nodes following inhaled delivery, indicating absorption of 5-FU in the bronchial tree and into the lymphatic path.

Safety

Inhalation was well tolerated by the normal lung tissue. No systemic hazardous effects were observed ${ }^{[32]}$. An overall response rate $>35 \%$ was observed. Out of 24 patients treated at a dose of $6.0 \mathrm{mg} / \mathrm{m}^{2}$, 6 showed a partial response, 1 showed complete response, 13 had stable disease and 4 showed no response.

Safety

No toxicity due to inhaled chemotherapy. In some patients, $>70 \%$ of the drug was delivered to one lung, indicating relative overdosing of that lung ${ }^{[33]}$. Inhaled doxorubicin showed dose-limiting toxicity. Patients showed high toxicity at a dose of $9.4 \mathrm{mg} / \mathrm{m}^{2}$ of inhaled doxorubicin; however, lower doses of inhaled doxorubicin were shown to be safe. Cough, chest pain, dyspnea, sore throat and fatigue were common side effects. Most adverse effects were pulmonary, with no systemic side effects. One patient had grade 3 hypoxia at a dose of $3.8 \mathrm{mg} / \mathrm{m}^{2}$, and one patient had a $>20 \%$ drop in forced vital capacity at a dose of $7.5 \mathrm{mg} / \mathrm{m}^{2[34]}$.

Inhaled carboplatin was shown to prolong the survival of lung cancer patients. Inhaled carboplatin provided improved anticancer efficacy compared with intravenous carboplatin. The response in patients receiving intravenous carboplatin and docetaxel was reported as 5 partial responders, 8 stable disease and 7 non-responders. The response in patients receiving inhaled and intravenous carboplatin was reported as 2 complete responders, 6 partial responders, 3 stable diseases, and 9 non-responders. The response in patients receiving inhaled carboplatin only was reported as 1 complete responder, 4 partial responders, 5 stable disease, and 10 non-responders.

\section{Safety}

Inhaled carboplatin caused less incidence of neutropenia than intravenous carboplatin and docetaxel. Inhaled carboplatin caused remissive cough and a decline in forced expiratory volume in $1 \mathrm{~s}^{[35]}$. Approximately half of inhaled gemcitabine was deposited in the lung, and the remaining drug was observed in the stomach and upper airways. Low plasma GCB levels were detected based on the pharmacokinetic data. The patient response was graded as 1 partial responder, 4 stable disease and 4 non-responders.

Safety

Limited systemic absorption and no severe systemic side effects were observed. One patient had bronchospasm. Other side effects included cough, nausea, fatigue and anorexia. The maximum tolerated dose of inhaled gemcitabine was $3 \mathrm{mg} / \mathrm{kg}^{[36]}$. may increase the risk of undesirable local toxicities. Overall, the effectiveness of inhaled chemotherapy against lung cancers is established, but there is considerable uncertainty regarding the toxicities of inhaled chemotherapy to healthy lung cells, making their safety a subject of constant debate. Hence, promoting uptake in cancer cells and minimizing accumulation in healthy cells may be a more effective approach to ensure the safety and efficacy of inhaled chemotherapy.

\section{Nano-carriers for inhaled drug delivery}

The delivery of anticancer drugs via nanoparticles has been shown to be efficacious and safe in a variety of cancers ${ }^{[60-62]}$.
Nanoparticles can encapsulate toxic anticancer drugs by biocompatible and biodegradable excipients and facilitate targeted and/or controlled delivery ${ }^{[63-67]}$. Anticancer drugs can also be formulated into drug nanocrystals with high drug loading and minimal use of excipients ${ }^{[68-70]}$. Thus, pulmonary administration of nanoparticles could also reduce the systemic toxicity of chemotherapeutic agents compared with free drugs. For example, Roa et al showed that inhaled doxorubicin nanoparticles exhibited lower cardiac toxicity compared with the same dose of free doxorubicin after intratracheal administration $^{[71]}$. Zou et al showed that paclitaxel-polyglutamic acid conjugate was well tolerated by mice following intratracheal 
administration $^{[72]}$. Furthermore, the sustained release characteristics of nanoparticles may further aid the effectiveness of inhaled chemotherapy by maintaining drug concentrations at tumor sites for longer durations ${ }^{[73-75]}$.

Due to their small size, nanoparticles inherently tend to penetrate and accumulate within the leaky tumor vasculature when a drug is delivered via systemic administration, which is termed the enhanced permeation and retention (EPR) effect ${ }^{[76-80]}$. The EPR effect may not play a role in tumor deposition when nanoparticles are administered via inhalation. However, delivery of the drug directly into the lungs enables passive targeting to the lung tumor. Furthermore, nano-carriers are taken up into the cancer cell via endocytosis, which typically does not occur in the case of solubilized drug $^{[81,82]}$. Thus, nanoparticles can increase penetration and accumulation of inhaled drugs in tumor tissues and cells, leading to improved anti-tumor activity compared with the free drug $^{[42,83-85]}$.

A large fraction of nanoparticles are taken up by the reticuloendothelial system (RES), such as the liver, kidney and spleen, following intravenous administration ${ }^{[85-87]}$, whereas the primary site of distribution of inhaled particles is the lungs. Thus, a relatively large fraction of nanoparticles is deposited in the lungs following inhalation compared to systemic delivery $^{[73,74,83-85,88,89]}$. However, the accumulation efficiency of nanoparticles in lung tumors following inhaled and systemic administration have not been thoroughly compared. Interestingly, inhaled doxorubicin-conjugated dendrimer showed better anticancer activity compared to systemic administration, indicating that there is a limited EPR effect in some lung tumors ${ }^{[90]}$.

Moreover, cellular uptake of particles is a particle sizedependent phenomenon and has been shown to increase with a decreasing particle size ${ }^{[91,92]}$. Hence, the selection of nanoparticles for inhaled delivery is inherently advantageous in terms of penetration-enhancing ability, as compared with microparticles. Roa et al showed that nanoparticles embedded in an effervescent carrier matrix facilitated the rapid release of primary nanoparticles and enhanced anti-tumor activity compared with those embedded in a non-effervescent carrier matrix following inhaled delivery ${ }^{[71]}$.

The ability of nanoparticles to release a chemotherapeutic agent in close proximity to the tumor is imperative to achieve selective and efficient tumor killing. However, premature release of encapsulated drug from nanoparticles may lead to non-specific toxicity to normal lung parenchyma. To circumvent this limitation, nanoparticles with site-specific and triggered release characteristics have been explored. Low extracellular and intracellular $\mathrm{pH}$ of tumor tissue/cells have been exploited to enable triggered release through the design of pH-sensitive fusogenic lipid nano-vesicles. These nanovesicles fuse with the cell plasma membrane and lysosomal membrane at low $\mathrm{pH}$, thus providing site-specific and triggered delivery of anticancer drugs to cancer cells ${ }^{[93-95]}$. It has been demonstrated that pulmonary surfactant mimetic $\mathrm{pH}$ sensitive nanoparticles are cytotoxic to lung tumor cells while being compatible with healthy lung cells, indicating a selective toxicity of the developed formulation to lung cancer cells ${ }^{[96]}$.

Nanoparticles can also be actively targeted to tumor cells by attaching tumor-specific ligands, which are thought to guide drug-loaded nanoparticles and facilitate specific interactions with lung cancer cells. Such targeting can inhibit the nonspecific interaction between drug-loaded nanoparticles and healthy lung cells and reduce local toxicity ${ }^{[90]}$. Lung cancer cells overexpress several receptors, such as epidermal growth factor receptor (EGF receptor), folate receptor, and luteinizing hormone-releasing hormone (LHRH receptors ${ }^{[97-104]}$. Tseng et al showed that EGF receptor-targeted biotinylated gelatin nanoparticles deposited more selectively into cancer cells owing to receptor-mediated uptake and caused no injury to the lungs ${ }^{[105,106]}$. EGF receptor-targeted inhalable magnetic nanoparticles demonstrated increased uptake in cancer cells compared with non-targeted particles and exhibited greater anti-tumor activities ${ }^{[107]}$. EGF receptor-targeted cisplatinloaded gelatin nanoparticles demonstrated greater lung deposition and retention, resulting in enhanced anti-tumor efficacy compared with free cisplatin or non-targeted nanoparticles ${ }^{[108]}$. Taratula et al developed LHRH peptide-coated mesoporous silica nanoparticles (MSNs) to deliver anticancer drugs (doxorubicin and cisplatin) and antisense oligonucleotides targeted to MRP1 and BCL-2 against resistant lung cancer. Inhalation allowed the deposition of higher drug/siRNA concentrations in the lungs compared to intravenous administration. The targeted nanoparticles were effectively internalized into human lung cancer cells and demonstrated an enhanced anticancer activity $^{[75]}$. Taratula et al also showed that lipid nanoparticle targeted to LHRH receptors can facilitate the selective deposition of doxorubicin and siRNA in lung tumor cells and minimize deposition in healthy lung tissues ${ }^{[109]}$.

Solid tumors are characterized by increased extracellular matrix deposition and tumor fibrosis ${ }^{[110,111]}$. This matrix is mainly composed of collagen networks and leads to the compartmentalization of tumors, which enhances tumor cell survival and proliferation ${ }^{[111-113]}$. Such a dense collagen network can inhibit nanoparticle penetration and distribution into the tumor ${ }^{[110,114-117]}$. Anti-fibrotic agents have been reported to decrease tumor interstitial fibrosis and promote the intratumoral distribution of nanoparticles ${ }^{[115,118]}$. Inhaled antifibrotic agents, ie, losartan and telmisartan, have also been shown to improve the uptake and accumulation of nanoparticles in lung cancer models ${ }^{[119]}$.

Overall, nanoparticles can improve the anti-tumor activity of loaded chemotherapeutics ${ }^{[120-123]}$. Nanoparticle-mediated inhaled chemotherapy has been shown to be safe and effective against lung cancer in pre-clinical and clinical studies (Table 2).

Drug resistance is another factor that can substantially compromise the therapeutic efficacy of chemotherapeutic agents against cancers. Lung cancers with acquired, ie, "pump" or "non-pump" resistance are less responsive to anticancer drugs $^{[128]}$. Pump resistance is typically associated with the expression of proteins such as multidrug resistance-associated protein (MRP) and P-glycoprotein, which can actively pump 
Table 2. Preclinical and clinical studies showing the safety and efficacy of nanoparticles in the pulmonary delivery of chemotherapeutic agents.

\begin{tabular}{ccc}
\hline Drug & Carrier & Outcome
\end{tabular}

Paclitaxel

Polyethylene glycol ${ }_{5000}$-distearoylphosphatidylethanolamine (PEG ${ }_{5000}$-DSPE) micelles

Doxorubicin

Human serum albumin (HSA) nanoparticles adsorbed with Apoptotic TRAIL protein (TRAIL/Dox HSA-NP)

Losartan and telmisartan

Polystyrene nanoparticles

Doxorubicin

Epirubicin
56-kDa PEGylated-polylysine dendrimer

Solid lipid nanoparticles
9-Bromo-noscapine

(9-Br-Nos)

Doxorubicin and cisplatin, two types of siRNA targeted to MRP1 and BCL2 mRNAs

Paclitaxel

Cisplatin Sustained release lipid inhalation targeting (SLIT)

Nanostructured lipid particles (NLPs)

Luteinizing hormone-releasing hormone receptortargeted mesoporous silica nanoparticles

Lung surfactant mimetic and pH-responsive lipid nanovesicles

9-Nitrocamptothecin

The lung targeting efficiency via the pulmonary route was 132 -fold higher than the intravenous route. Micelles substantially reduced the distribution of paclitaxel in non-targeted tissues compared with free paclitaxel following intratracheal administration. Micelles showed no sign of inflammation in lung tissues, highlighting the safety and suitability of the delivery vehicle for inhaled delivery ${ }^{[74]}$.

Inhaled TRAIL/Dox HSA-NP nanoparticles were distributed effectively throughout the lungs and provided sustained drug release. Inhaled TRAIL/Dox HSA-NP also expressed greater anti-tumor activity compared with TRAIL or Dox HSA-NP alone, with minimal side effects ${ }^{[124]}$. Losartan and Telmisartan showed significant in vivo anticancer activity against orthotopic and metastatic lung cancers. Animals receiving inhaled losartan and Telmisartan survived longer than untreated animals. The drugs were well tolerated by normal lung tissues ${ }^{[119]}$.

The dendrimer expressed improved anti-tumor activity following intratracheal administration compared with the drug solution administered intravenously. The drug-dendrimer complex was better tolerated by the lungs than free drug after intratracheal administration ${ }^{[00]}$. Epirubicin concentration in the lungs was higher than in plasma following inhaled nanoparticle therapy. The drug concentration in the lungs was higher with inhaled epirubicin nanoparticles compared with inhaled epirubicin solution ${ }^{[125]}$.

The half-life of 9-Br-Nos-NLPs increased in the lungs compared with free drug powder after inhalation ${ }^{[73]}$. Inhalation led to greater amounts of drugs and siRNA to be retained in the lungs than intravenous administration of the same formulation. Inhaled delivery also restricted the systemic uptake and accumulation of nanoparticles in other organs ${ }^{[75]}$.

Fusogenicity of the nanoparticles enabled cytosolic delivery of paclitaxel to cancer cells but was non-toxic to normal cells. Inhaled delivery of drug-loaded nanoparticles led to lower drug concentrations in non-targeted sites (liver, spleen and plasma) compared with intravenous paclitaxel solution. Drug-loaded nanoparticles showed no lung toxicity ${ }^{[96]}$.

Inhaled cisplatin liposomes were well tolerated with no signs of systemic (nephrotoxicity, ototoxicity, or neurotoxicity) toxicity in lung cancer patients, which was attributed to a low systemic drug concentration. Side effects, including nausea, vomiting, dyspnea, fatigue and hoarseness, were observed ${ }^{[126]}$.

Inhaled 9-Nitrocamptothecin liposomes were safe and enabled disease stabilization in some lung cancer patients. The drug was also systemically absorbed following inhalation at high doses, leading to systemic side effects, including anemia, neutropenia and anorexia. A partial remission of liver metastasis was also observed in a patient with endometrial cancer, indicating the systemic potential of inhaled administration ${ }^{[127]}$. 
anticancer drugs out of cancer cells, reducing their intracellular concentration and consequently effectiveness ${ }^{[129]}$. Nonpump resistance is caused by the activation of anti-apoptotic cellular defense due to the upregulation of B-cell lymphoma-2 (BCL-2) protein, which prevents the release of cytochrome $c$ and hence the execution of caspase-mediated cell apoptosis ${ }^{[130,131]}$. Suppression of drug resistance-associated proteins such as BCL-2 protein and MRP could reduce the efflux of anticancer drug and promote apoptosis sensitivity against anti-tumor drugs. Nanoparticles can co-deliver anticancer drugs with genes and other adjuvants to effectively suppress these resistance mechanisms and increase the sensitivity of such resistant cancer cells against chemotherapies ${ }^{[75,109,132,133]}$. Garbuzenko et al developed inhaled nanoparticles containing doxorubicin in combination with antisense oligonucleotides targeted to MRP1 mRNA as a suppressor of pump resistance and BCL-2 mRNA (as a suppressor of non-pump resistance) for lung cancer. This formulation has been shown to enhance the sensitivity of lung cancer to anticancer drugs, increasing the efficacy upon inhalation $^{[132]}$.

\section{Physiological barriers to inhaled drug delivery}

For inhaled chemotherapy, drugs should be deposited and retained in the lungs at therapeutically effective concentrations to elicit an efficient anti-tumor effect. However, the architecture of the respiratory tract and clearance mechanisms of the lungs pose a key challenge to the deposition and retention of inhaled nanoparticles in the lungs. To effectively address these issues, it is important to understand the barriers to deposition and retention of inhaled nanoparticles. The current understanding of the deposition and clearance behaviors of inhaled nanoparticle is largely derived from studies investigating the clearance of environmental nanoparticle pollutants, which can be extrapolated to drug nanoparticles to a certain extent ${ }^{[134,135]}$.

\section{Deposition of inhaled particles}

The lungs are composed of a series of branching airways, which can be classified into the conducting zone and the respiratory zone. The conductive zone or upper airway consists of the trachea, which divides into two bronchi and further subdivides into bronchioles, whereas the respiratory zone, or the deep lung, includes the respiratory bronchioles, the alveolar ducts and the alveolar sacs.

Inhaled particles are carried with tidal air through the respiratory tracts. Particulate properties such as geometric size, shape and density determine the inertia acting on particles during their travel through the airway and thereby determine their deposition along the respiratory tract ${ }^{[136-138]}$. This aerodynamic behavior is often characterized by the aerodynamic diameter, which represents the diameter of a sphere of unit density. Particles of the same aerodynamic diameter reach the same velocity in the air stream as the particle of interest of arbitrary density. Particle measurement techniques, such as light scattering, laser diffraction or image analysis, provide geometric diameters, which can be converted to the aerody- namic diameter using a widely accepted model that describes the relationship between the geometric diameter, density and aerodynamic diameter ${ }^{[139]}$ :

$$
D_{\mathrm{a}}=D_{\mathrm{g}} * \sqrt{\frac{\rho}{\chi \rho_{0}}}
$$

Where $D_{\mathrm{a}}$ is the aerodynamic diameter, $D_{\mathrm{g}}$ is the geometric diameter, $\rho_{0}$ is the unit particle density, $\rho$ is the particle density, and $\chi$ is the dynamic shape factor of the particle.

Based on the aerodynamic diameter, inhaled particles are believed to distribute along the airways via three main mechanisms: inertial impaction, gravitational sedimentation and diffusion $^{[140,141]}$. Particles with an aerodynamic diameter $>5$ $\mu \mathrm{m}$ lack the ability to change their trajectories with the tidal air, leading to impaction and deposition in the upper airways. The main mechanism of deposition is thus inertial impaction $^{[142-144]}$. Particles with an aerodynamic diameter between 1 and $5 \mu \mathrm{m}$ are believed to deposit mostly in the lower airways (bronchioles and alveoli) via the mechanism of gravitational sedimentation $^{[145]}$. Particles with an aerodynamic diameter smaller than $1 \mu \mathrm{m}$ remain suspended in the airstream and are likely exhaled after inhalation without being deposited in the airway. The main deposition mechanism for these particles is diffusion ${ }^{[145,146]}$. Interestingly, as the particle size decreases to less than approximately $500 \mathrm{~nm}$, lung deposition may increase $^{[147-149]}$.

For medications targeting the lower airways (ie, the deep lung), particles with an aerodynamic diameter of $1-5 \mu \mathrm{m}$ are highly desirable. The performance of inhaled formulations is often described in terms of the fraction or dose of particles in the size range of $1-5 \mu \mathrm{m}$, which is termed as the fine particle fraction (FPF) or fine particle dose (FPD). Alternatively, the mass median aerodynamic diameter (MMDA), which is defined as the aerodynamic diameter at which $50 \%$ of the particles are smaller, can also be used as an indicator of the aerosol property of inhaled formulations ${ }^{[138]}$.

\section{Clearance of particles in the respiratory tract}

Depending on the regional distribution and particle properties, inhaled particles are cleared primarily via three mechanisms: muco-ciliary clearance, phagocytosis, and systemic uptake $^{[150]}$.

Muco-ciliary clearance is the dominant clearance mechanism in the upper airway ${ }^{[151]}$. The ciliated columnar epithelium secretes mucus, which traps the particles deposited in the upper airways. These entrapped particles are propelled by the action of beating cilia in a proximal direction, causing them to be coughed out or swallowed. The majority of insoluble particles with a size $>5 \mu \mathrm{m}$ deposited in upper airways and are eliminated via muco-ciliary clearance ${ }^{[152]}$. Smaller particles are deposited in the deep lungs where muco-ciliary clearance is less functional and thus are retained longer than larger insoluble particles $^{[135,152-154]}$. Macrophages are also present in the upper airway, but phagocytosis is less dominant in this region ${ }^{[134,155]}$.

The clearance mechanisms in the deep lungs are relatively complex and depend on particle properties such as dissolu- 
tion kinetics. Slowly dissolving or insoluble particles may interact with epithelial and immune cells in the lungs and be removed by muco-ciliary clearance, phagocytosis via alveolar macrophages, and endocytosis ${ }^{[156-158]}$. Phagocytosis by alveolar macrophages is believed to be the dominant clearance mechanism in the deep lungs ${ }^{[159,160]}$. This process involves particle internalization by macrophages, followed by lysosomal digestion or removal of particle-loaded macrophages into the lymph or via muco-ciliary clearance ${ }^{[161-166]}$. Phagocytosis by macrophages is mainly responsible for clearance of particles between 1 and $5 \mu \mathrm{m}$ in size ${ }^{[167-170]}$. Particles with a size $<200$ $\mathrm{nm}$ are not recognized by macrophages due to their small size $^{[153,171]}$ and/or rapid uptake by epithelial cells ${ }^{[172]}$. The role of protein/receptor-mediated uptake has been highlighted in the translocation of a small fraction of inhaled nanoparticles to the systemic circulation ${ }^{[152,153,161,173]}$. Intact nanoparticles may also enter the systemic circulation by endocytosis via alveolar caveolae $^{[158]}$.

Nanoparticles that undergo quick dissolution after deposition in the deep lungs may rapidly release drug, which can be absorbed into the systemic circulation ${ }^{[162,163,174]}$. The rate of absorption of a drug molecule is closely associated with its lipophilicity and molecular weight, whereby low-molecularweight lipophilic drugs are the most rapidly absorbed.

\section{Improving lung deposition}

Particulate properties such as particle size, density, and surface composition play a vital role in developing effective inhalable medicines by determining the site of deposition. Thus, developing formulations with appropriate particulate properties is key to the effectiveness of inhaled medicines. Individual nanoparticles with sizes $<500 \mathrm{~nm}$ tend to agglomerate due to strong cohesive forces, resulting in aggregates of uncontrolled sizes $^{[175-177]}$. These aggregates are difficult to disperse into individual nanoparticles after inhalation, leading to inconsistent, unpredictable and often poor aerosolization ${ }^{[84,178]}$. Hence, nanoparticles are often administered as particles/droplets with 1-5 $\mu \mathrm{m}$ aerodynamic diameters. Nebulizer devices can convert nanoparticle suspensions into highly inhalable droplets. Alternatively, particle engineering can convert nanoparticles into uniformly sized inhalable particles.

\section{Nanoparticles as inhalable droplets}

Typically, nanoparticle suspensions are aerosolized into droplets with appropriate aerodynamic diameters using currently available inhalation devices. Nebulizers and pressurized Metered Dose Inhalers (pMDI) are employed to assist nanoparticle inhalation.

\section{Nebulizers}

The nebulizer is the most commonly used device for inhaled delivery of nanoparticle suspensions ${ }^{[179]}$. In general, nebulizers utilize compressed air to convert a suspension of nanoparticles into inhalable droplets ${ }^{[180]}$. For example, aerosolization of telmisartan and losartan bearing a solid lipid nanoparticle suspension using a jet nebulizer resulted in a FPF $>70 \%$ and was deposited into the lungs in separate in vivo inhalation experiments ${ }^{[119]}$. Aerosols of nanoparticle suspensions exhibit a higher FPF than drug solutions after nebulization, indicating the suitability of nanoparticles for inhalation delivery ${ }^{[96,125]}$. There have been concerns about the negative effects of nebulization on the structure of delivery vehicles, especially lipid-based particles as well as susceptible drugs and genes ${ }^{[181]}$. Mainelis et al demonstrated that the one-jet collision nebulizer facilitated the deposition of liposomes containing doxorubicin and siRNA into the deep lungs without compromising liposome integrity and the biological activity of susceptible antisense oligonucleotide ${ }^{[182]}$. The bulky traditional jet nebulizers are not convenient to use; more portable and efficient nebulizers, such as vibrating mesh nebulizers, have recently been developed ${ }^{[180,183-186]}$. The mesh nebulizer was used to aerosolize a paclitaxel lipid nanocapsule suspension and showed an FPF $>80 \%$ without altering the primary properties of the lipid nanocapsules ${ }^{[181]}$.

\section{Pressurized metered dose inhaler (pMDI)}

The pressurized metered dose inhaler (pMDI) creates small inhalable droplets of drug suspended in compressed propellant (ie, hydrofluoroalkane [HFA]). The small size of pMDI devices thus offer greater portability and can be used for inhaled delivery of the nanoparticle suspension. Conti et al showed that pMDI can convert a dendrimer-siRNA complex suspension into highly respirable droplets, leading to an FPF of $77 \%$. The integrity and biological activity of siRNA in dendriplexes formulated for pMDIs remained intact after longterm exposure to the propellant $\mathrm{HFA}^{[187]}$. However, the application of pMDI technology is limited due to the typically low efficiency, with only approximately $10 \%$ of the aerosol emitted from pMDIs being deposited in the deep lungs ${ }^{[188]}$. Usage error by patients who lack hand-mouth coordination may also lead to low delivered doses ${ }^{[189-191]}$. Furthermore, pMDIs are unable to deliver high-dose medications ${ }^{[180]}$.

\section{Nanoparticles as inhalable particles}

Delivery of nanoparticles as a suspension often requires the nanoparticles to be stored in a liquid medium. Long-term storage as a liquid suspension may lead to physico-chemical instabilities such as aggregation, hydrolysis of polymer and drug leakage/degradation ${ }^{[192,193]}$. Formulating nanoparticles as a dry powder offers greater long-term stability than as a suspension $^{[192,193]}$. Additionally, the majority of DPIs are breath actuated, avoiding the problem of coordinated inspiration and actuation. Controlling the size of nanoparticles is central for their formulation into reliable and efficient inhalable dry powders. Nanoparticles can be dried with/without excipients via spray-drying, freeze-drying and spray freeze-drying to generate stable and uniformly sized inhalable particles. A number of strategies have been explored to engineer nanoparticles into inhalable particles, which are discussed below.

\section{Blending with carrier particles}

Small particles with sizes $<10 \mu \mathrm{m}$ are highly cohesive and exhibit poor flow and inhalation performance ${ }^{[194,195]}$. Such 
cohesive particles are often formulated as "interactive mixtures" to improve their flow and dispersibility ${ }^{[196]}$. Interactive mixtures represent powders in which small particles are adhered to the surfaces of large carrier particles ${ }^{[197-199]}$. Kalantarian et al showed that mixing of 5-FU nanoparticles with lactose particles (Pharmatose ${ }^{\circledR} 80$ ) led to a low FPF of $\sim 20 \%{ }^{[178]}$. Such a low efficiency of interactive mixtures is often attributed to inefficient de-agglomeration and poor detachment of drug particles from carrier particles upon inhalation ${ }^{[200]}$.

\section{Enlargement by co-drying with carrier/excipient}

\section{Nanoparticle aggregates}

Co-drying nanoparticles with excipients lead to the formation of inhalable nanoparticle aggregates in an excipient matrix $^{[201-203]}$. Azarmi et al used spray-freeze-dried doxorubicin nanoparticles with lactose to produce particles with an aerodynamic diameter of $\sim 3 \mu \mathrm{m}^{[204]}$. FPF of the PLGA nanoparticle containing 6-3-hydroxyl-7H-indeno[2,1-c]quinolin-7-one dihydrochloride (TAS-103) improved from $<1 \%$ to $>10 \%$ after spray-drying with trehalose ${ }^{[84]}$, although it still displayed low aerosol performance. Upon inhalation, TAS-103-loaded PLGA nanoparticles provided 300 times higher drug concentration in the lungs of rats than those in plasma. The drug lung concentrations in rats were also 13-fold higher with TAS-103-loaded PLGA nanoparticles compared with the free drug administered via the intravenous route ${ }^{[84]}$. Some studies have shown that the carrier excipients dissolve and release primary nanoparticles upon deposition and thus achieve the aerosolization properties of microparticles while maintaining the release benefit of nanoparticles ${ }^{[84,204,205]}$. L-leucine is a commonly used force-control agent that is known to reduce inter-particle cohesion and improve the dispersibility of small particles $^{[206,207]}$. El-Gendy et al showed that the particle sizes of paclitaxel-cisplatin nanoparticles and L-leucine freezedried nano-aggregates were $\sim 1-5 \mu \mathrm{m}$, which demonstrated an excellent FPF of $>70 \%$. Furthermore, L-leucine showed no cytotoxic effect up to $5 \mathrm{mg} / \mathrm{mL}$ in A549 cells ${ }^{[208]}$. Varshosaz et al spray-dried doxorubicin-loaded bovine serum albumin nanoparticles with trehalose, mannitol and L-leucine in which mannitol enabled a higher FPF than trehalose; L-leucine was abandoned in this study due to the formation of irregularly shaped particles ${ }^{[209]}$.

\section{Effervescent particles}

Ely et al introduced the effervescent technology, which involves spray-drying nanoparticles with effervescent excipients to enhance aerosolization and provide an effervescent effect for the quick release of nanoparticles upon dissolution of the excipients in aqueous media ${ }^{[210]}$. The effervescent effect is typically achieved by the combination of sodium bicarbonate and citric acid with ammonia. The $\mathrm{pH}$ of the feed solution is kept low to retard effervescing during the particle formation or drying process ${ }^{[210]}$. The effervescent technology has also been explored to facilitate inhaled delivery of nanoparticles against lung cancer. Azarmi et al showed that nanoparticles spray-dried with effervescent excipients achieved an MMAD of $\sim 5 \mu \mathrm{m}$, and animals (BALB/c nude mice) receiving effervescent particles showed no change in body weight or morbidity, indicating the safety and tolerability of the inhaled carrier system $^{[211]}$. It has been shown that an effervescent carrier containing doxorubicin-loaded NP nanoparticles distributed throughout the lungs and released primary nanoparticles in the lungs ${ }^{[212]}$. Mice receiving doxorubicin-loaded n-butylcyanoacrylate nanoparticles that were spray-freeze-dried with effervescent excipients survived longer compared with those receiving intravenous doxorubicin solution or inhaled free doxorubicin $^{[71]}$. Jyoti et al demonstrated that effervescent carriers improved the aerosolization and also increased the release of anticancer agent (9-bromo-noscapine) from the nanoparticles, leading to greater anticancer activity compared with noneffervescent carriers ${ }^{[73]}$.

\section{Improving tumor targeting}

Lung cancer cells are often located at specific sites in the lungs (ie, only in one lobe). However, inhaled chemotherapeutic agents may distribute uniformly throughout the lungs. Targeting inhaled nanoparticles specifically to the tumor cells is another approach to improve the safety and efficacy of inhaled chemotherapy.

\section{Magnetic targeting}

Drugs co-formulated with magnetically active particles can be guided to a specific location in the body using a strong external magnet ${ }^{[213-216]}$. As this process involves physical force to facilitate drug targeting, this concept of drug delivery is termed physical targeting. A range of pure metals and alloys can be used for this purpose, including iron oxide, cobalt, nickel, platinum and magnesium ${ }^{[217]}$. Magnetic nanoparticles have been shown to facilitate drug deposition in specific lung regions of mice with the help of a permanent magnet ${ }^{[218-221]}$. McBride et al spray-dried superparamagnetic iron oxide nanoparticles (SPIONs) with lactose and doxorubicin to form particles with an aerodynamic diameter of $3.27 \pm 1.69 \mu \mathrm{m}$. Such formulations showed more than twice the spatial deposition and retention in the regions under the influence of a strong magnetic gradient compared to a liquid suspension in an in vitro tracheal mimic study ${ }^{[222]}$. Verma et al showed that inhaled quercetin-loaded PLGA-coated magnetic $\left(\mathrm{Fe}_{3} \mathrm{O}_{4}\right)$ nanoparticles showed marked in vitro anticancer activity and were well tolerated in mice with no signs of lung toxicity ${ }^{[223]}$.

\section{Reducing phagocytic clearance}

Particle engineering provides efficient control over particle size to generate inhalable nanoparticles and minimize mucociliary clearance in the upper airways. Nevertheless, particles deposited in the deep lungs are still subjected to clearance by phagocytosis, which can reduce the efficacy of inhaled chemotherapy. Alveolar macrophages can engulf particles $<5 \mu \mathrm{m}$, depending on their physico-chemical properties such as size and surface chemistry ${ }^{[224-226]}$. Thus, an ideal pulmonary delivery system should circumvent the clearance of drug from the lungs. Unfortunately, only a few investigations have studied 
the effect of phagocytosis on the anti-tumor efficacy of inhaled nanoparticulate chemotherapeutics.

\section{Large porous particles}

Edward et al introduced the concept of large porous particles, which possess large geometric sizes $\sim 10 \mu \mathrm{m}$ but exhibit aerodynamic diameters $<5 \mu \mathrm{m}$ due to their low density ${ }^{[227-229]}$. The large sizes of these porous particles enable them to overcome interparticle forces, facilitating good aerosol performance and improving deposition in the deep lungs. Moreover, such large particles may escape phagocytosis by alveolar macrophages ${ }^{[227,228,230]}$. Spray-drying emulsions containing phospholipids and propellants have been developed to produce low-density hollow particles $^{[227,228,230-232]}$.

Recent studies have shown the feasibility of using porous particles to improve the inhalation of nanoparticles. Tsapsis et al reported that nanoparticles can form large porous/hollow 'Trojan' particles under specific spray-drying conditions with or without excipients, which can disintegrate into individual nanoparticles upon reconstitution ${ }^{[225]}$. It was proposed that spray drying conditions that generated high Péclet numbers could form large porous particles ${ }^{[225]}$. The Péclet number is dimensionless and describes the mass transport of solutes in drying droplets. It is defined by the following equation ${ }^{[225]}$ :

$$
P_{\mathrm{e}}=\frac{R^{2}}{D T_{\mathrm{d}}}
$$

where $P_{\mathrm{e}}$ is the Péclet number, $R$ is the radius of the droplet, $D$ is the diffusion coefficient of the nanoparticle, and $T_{\mathrm{d}}$ is the time required for the droplet to dry.

When $P_{\mathrm{e}} \ll 1$, nanoparticles diffuse towards the center of the receding droplet by diffusion, yielding relatively dense dried particles. However, when $P_{\mathrm{e}} \gg 1$, nanoparticles do not have enough time to redistribute to the center of the receding droplet, leading to their accumulation at the air-water interface. Further drying leads nanoparticles to be held together by physical forces (eg, van der Waals forces) or embedded in an excipient matrix forming a shell earlier in the drying phase. The increased vapor pressure ruptures the cell, and water vapors escape in the final phase of drying leading to formation of porous particles ${ }^{[225]}$. The physical properties, including the porosity and morphology of such large porous particles, were shown to depend on the nanoparticle size, chemical nature, excipients used, and nanoparticle concentration in the resultant particles ${ }^{[224,225,233]}$. Hadinoto et al investigated the effect of phospholipids on the formation of such large porous particles. The phospholipid concentration was shown to govern the degree of hollowness of the resultant particles ${ }^{[224]}$. Furthermore, the release of drugs was shown to depend on the degree of hollowness ${ }^{[233]}$. However, to date, no studies have employed the porous particle platform for the inhaled delivery of anticancer drugs, which could be potentially useful for inhaled chemotherapy.

\section{Swellable hydrogel particles}

El-Sherbiny et al developed swellable hydrogel particles as carri- ers to prevent macrophage uptake of nanoparticles ${ }^{[234,235]}$. PEGg-NPHCs self-assembled nanoparticles of a model protein, bovine serum albumin (BSA), were prepared and encapsulated in sodium alginate via spray-drying followed by ionotropic gelation using $\mathrm{Ca}^{2+}$ ions. The coated particles had aerodynamic diameters of $\sim 3 \mu \mathrm{m}$ and a relatively low FPF of $\sim 30 \%$. The microspheres showed swelling that was followed by enzymatic degradation ${ }^{[235]}$. The coated hydrogel particles demonstrated significantly delayed phagocytosis ${ }^{[234]}$. Such swellable hydrogel inhalable particle may be attractive for inhaled delivery of nanoparticulate chemotherapy against lung cancers.

\section{Surface-modified particles}

Surface coating and conjugation of actives with polyethylene glycol (PEG) have been shown to reduce clearance from the lungs. This phenomenon was attributed to the ability of PEG to facilitate muco-penetration and reduce uptake by alveolar macrophages ${ }^{[226,236-239]}$. Luo et al demonstrated that the conjugation of paclitaxel with PEG not only improved its lung residence time but also enhanced the anticancer activity in a mouse model of lung cancer ${ }^{[240]}$. Paclitaxel conjugated with higher-molecular-weight PEG demonstrated greater in vivo anti-tumor activity compared with lower-molecular-weight $\mathrm{PEG}^{[240]}$. PEGylation was also shown to reduce the lung inflammation and enable a higher tolerable dose than using free paclitaxel alone ${ }^{[240]}$.

Surface coating of particles with a lung surfactant (1,2-dipalmitoylphosphatidylcholine [DPPC]) has also been shown to reduce phagocytosis ${ }^{[241,242]}$. In the presence of phospholipids, the adsorption of opsonic proteins on inhaled particles is inhibited, which allows inhaled particles to escape phagocytosis ${ }^{[241,242]}$. Meenach et al generated inhalable lung surfactantmimic phospholipid and PEGylated lipopolymer nanoparticles using advanced organic spray-drying process ${ }^{[243]}$. Spraydrying at optimal temperatures facilitates the formation of more inhalable particles ${ }^{[243]}$. Inhalable lung surfactant (DPPC/ DPPG)-based carrier particles loaded with paclitaxel demonstrated an excellent FPF of $>70 \%$ and enhanced anti-tumor activity compared with free paclitaxel ${ }^{[244]}$. However, in vivo studies investigating the efficacy of such inhalable surfactant modified nanoparticles against lung cancer are scarce.

\section{Conclusion}

Chemotherapy through pulmonary delivery is believed to achieve much higher drug concentrations in the lungs and reduce systemic drug exposure. This technology could offer a promising alternative to the oral and parenteral delivery of chemotherapies for the treatment of lung cancers. Nevertheless, effect of high concentrations of inhaled anticancer drugs in the lungs centers on local toxicity remain largely unknown. Moreover, the distributions of most inhaled free anticancer drugs in the lungs are not tumor-specific. Nanoparticle formulations are promising for the inhaled delivery of chemotherapeutics against lung cancer. Nanoparticles may encapsulate toxic drugs and release them in a more site-specific 
and controlled manner. Additionally, nanoparticles can carry multiple drugs, DNAs and RNAs, as well as imaging agents.

Recent research efforts have focused on enhancing the lung tumor deposition of inhaled drug delivery systems as well as minimizing their clearance from the lungs to maximize the efficacy and control the side effects. There are a few challenges for the pulmonary delivery of nanoparticles, largely stemming from their extremely low mass and cohesive nature.

Only the fraction of drug liberated from nanoparticles is able to exert anticancer activity. Due to analytical limitations, it is difficult to quantify the fraction of drug liberated from the nanoparticles rather than the total bound and unbound fraction of drug, making it difficult to assess the true potential of nanoparticles for improving drug penetration/uptake. Furthermore, the drug is typically quantified in the whole lung rather than the lung tumor, which may further add to the uncertainty about the true targeting potential and hence the anti-tumor efficacy of nanoparticles. Moreover, physicians typically prefer systemic routes over the inhaled route due to greater predictability and reliability (drug deposition may vary due to different lung functions of the patients). Thus, further improvement of aerosolization technology to enhance control over the dose, reliability and predictability of the inhaled drug fraction is desirable.

It is possible to utilize particle engineering and ensure consistent and highly efficient delivery of nanoparticles to the lungs through nano-aggregates, large porous particles, and other formulation techniques. Furthermore, physical targeting by magnetic nanoparticles and active targeting by ligand anchoring have shown the potential to enhance tumor targeting and improve the efficacy of inhaled anticancer drugs. Nanoparticles have also been shown to facilitate the codelivery of anticancer drug with anti-sense oligonucleotides, making them an attractive candidate against drug-resistant lung cancers. Particle size enlargement and surface modification (eg, with PEG and surfactants) have been suggested to be effective for reducing the phagocytic clearance of nanoparticle formulations. In conclusion, inhaled nano-particulate chemotherapy bears great potential for the treatment of lung cancer. Efforts are needed to further investigate the safety and efficacy of this technology in clinical settings.

\section{References}

1 Ettinger DS, Akerley W, Bepler G, Blum MG, Chang A, Cheney RT, et al. Non-small cell lung cancer. J Natl Compr Canc Netw 2010; 8: 740-801.

2 Cancer facts \& figures. American Cancer Society 2016.

3 Jemal A, Center MM, Ward E. The convergence of lung cancer rates between blacks and whites under the age of 40, United States. Cancer Epidemiol Biomarkers Prev 2009; 18: 3349-52.

4 Jemal A, Bray F, Center MM, Ferlay J, Ward E, Forman D. Global cancer statistics. CA Cancer J Clin 2011; 61: 69-90.

5 Shepherd FA, Crowley J, Van Houtte P, Postmus PE, Carney D, Chansky $\mathrm{K}$, et al. The international association for the study of lung cancer lung cancer staging project: proposals regarding the clinical staging of small cell lung cancer in the forthcoming (seventh) edition of the tumor, node, metastasis classification for lung cancer. J
Thorac Oncol 2007; 2: 1067-77.

6 Rapp E, Pater JL, Willan A, Cormier Y, Murray N, Evans WK, et al. Chemotherapy can prolong survival in patients with advanced nonsmall-cell lung cancer - report of a Canadian multicenter randomized trial. J Clin Oncol 1988; 6: 633-41.

7 Langley RR, Fidler IJ. Tumor cell-organ microenvironment interactions in the pathogenesis of cancer metastasis. Endocr Rev 2007; 28: 297-321.

8 Langley RR, Fidler IJ. The seed and soil hypothesis revisited-The role of tumor-stroma interactions in metastasis to different organs. Int J Cancer 2011; 128: 2527-35.

9 Chen LL, Blumm N, Christakis NA, Barabasi AL, Deisboeck TS. Cancer metastasis networks and the prediction of progression patterns. Br J Cancer 2009; 101: 749-58.

10 Riihimäki M, Hemminki A, Fallah M, Thomsen H, Sundquist K, Sundquist J, et al. Metastatic sites and survival in lung cancer. Lung Cancer 2014; 86: 78-84.

11 López Rodríguez M, Cerezo Padellano L. Toxicity associated to radiotherapy treatment in lung cancer patients. Clin Transl Oncol 2007; 9: 506-12.

12 Spiro SG, Porter JC. Lung cancer - where are we today? Am J Respir Crit Care Med 2002; 166: 1166-96.

13 Arriagada R, Bergman B, Dunant A, Le Chevalier T, Pignon JP, Vansteenkiste J. Cisplatin-based adjuvant chemotherapy in patients with completely resected non-small-cell lung cancer. N Engl J Med 2004; 350: 351-60.

14 Splinter TA, Sahmoud T, Festen J, van Zandwijk N, Sorenson S, Clerico $\mathrm{M}$, et al. Two schedules of teniposide with or without cisplatin in advanced non-small-cell lung cancer: a randomized study of the european organization for research and treatment of cancer lung cancer cooperative group. J Clin Oncol 1996; 14: 127-34.

15 Bunn PA Jr, Kelly K. New chemotherapeutic agents prolong survival and improve quality of life in non-small cell lung cancer: a review of the literature and future directions. Clin Cancer Res 1998; 4: 1087 100.

16 Spiro SG, Rudd RM, Souhami RL, Brown J, Fairlamb DJ, Gower NH, et al. Chemotherapy versus supportive care in advanced non-small cell lung cancer: improved survival without detriment to quality of life. Thorax 2004; 59: 828-36.

17 Minchinton Al, Tannock IF. Drug penetration in solid tumours. Nat Rev Cancer 2006; 6: 583-92.

18 Sriraman SK, Aryasomayajula B, Torchilin VP. Barriers to drug delivery in solid tumors. Tissue Barriers 2014; 2: e29528.

19 Bahl A, Falk S. Meta-analysis of single agents in the chemotherapy of NSCLC: what do we want to know? Br J Cancer 2001; 84: 11435.

20 Tannock I. Cell kinetics and chemotherapy: a critical review. Cancer Treat Rep 1978; 62: 1117-33.

21 Hosomi Y, Shibuya M, Niho S, Ichinose Y, Kiura K, Sakai H, et al. Phase II study of topotecan with cisplatin in Japanese patients with small cell lung cancer. Anticancer Res 2011; 31: 3449-56.

22 Schiller JH, Kim K, Hutson P, DeVore R, Glick J, Stewart J, et al. Phase II study of topotecan in patients with extensive-stage small-cell carcinoma of the lung: an Eastern Cooperative Oncology Group Trial. J Clin Oncol 1996; 14: 2345-52.

23 Mavroudis D, Veslemes M, Kouroussis C, Tzanakis N, Ferdoutsis E, Toumbis $\mathrm{M}$, et al. Cisplatin-etoposide alternating with topotecan in patients with extensive stage small cell lung cancer (SCLC). A multicenter phase II study. Lung Cancer 2002; 38: 59-63.

24 Clegg A, Scott DA, Sidhu M, Hewitson P, Waugh N. A rapid and systematic review of the clinical effectiveness and cost-effectiveness 
of paclitaxel, docetaxel, gemcitabine and vinorelbine in non-small-cell lung cancer. Health Technol Assess 2001; 5: 1-195.

25 Kemeny NE, Niedzwiecki D, Hollis DR, Lenz HJ, Warren RS, Naughton MJ, et al. Hepatic arterial infusion versus systemic therapy for hepatic metastases from colorectal cancer: a randomized trial of efficacy, quality of life, and molecular markers (CALGB 9481). J Clin Oncol 2006; 24: 1395-403.

26 Guerin C, Olivi A, Weingart JD, Lawson HC, Brem H. Recent advances in brain tumor therapy: local intracerebral drug delivery by polymers. Invest New Drugs 2004; 22: 27-37.

27 Markman M, Cleary S, Pfeifle C, Howell SB. Cisplatin administered by the intracavitary route as treatment for malignant mesothelioma. Cancer 1986; 58: 18-21.

28 Duvillard C, Romanet P, Cosmidis A, Beaudouin N, Chauffert B. Phase 2 study of intratumoral cisplatin and epinephrine treatment for locally recurrent head and neck tumors. Ann Otol Rhinol Laryngol 2004; 113: 229-33.

29 Markman M. An update on the use of intraperitoneal chemotherapy in the management of ovarian cancer. Cancer J 2009; 15: 105-9.

30 Markman M, Reichman B, Hakes T, Rubin S, Lewis JL Jr, Jones W, et al. Evidence supporting the superiority of intraperitoneal cisplatin compared to intraperitoneal carboplatin for salvage therapy of smallvolume residual ovarian cancer. Gynecol Oncol 1993; 50: 100-4.

31 Tatsumura T, Yamamoto K, Murakami A, Tsuda M, Sugiyama S. New chemotherapeutic method for the treatment of tracheal and bronchial cancers--nebulization chemotherapy. Gan No Rinsho 1983; 29: 765-70.

32 Tatsumura T, Koyama S, Tsujimoto M, Kitagawa M, Kagamimori S. Further study of nebulisation chemotherapy, a new chemotherapeutic method in the treatment of lung carcinomas: fundamental and clinical. Br J Cancer 1993; 68: 1146-9.

33 Otterson GA, Villalona-Calero MA, Hicks W, Pan X, Ellerton JA, Gettinger SN, et al. Phase I/II study of inhaled doxorubicin combined with platinum-based therapy for advanced non-small cell lung cancer. Clin Cancer Res 2010; 16: 2466-73.

34 Otterson GA, Villalona-Calero MA, Sharma S, Kris MG, Imondi A, Gerber M, et al. Phase I study of inhaled doxorubicin for patients with metastatic tumors to the lungs. Clin Cancer Res 2007; 13: 1246-52.

35 Zarogoulidis P, Eleftheriadou E, Sapardanis I, Zarogoulidou V, Lithoxopoulou $\mathrm{H}$, Kontakiotis $\mathrm{T}$, et al. Feasibility and effectiveness of inhaled carboplatin in NSCLC patients. Invest New Drugs 2012; 30: 1628-40.

36 Lemarie E, Vecellio L, Hureaux J, Prunier C, Valat C, Grimbert D, et al. Aerosolized gemcitabine in patients with carcinoma of the lung: feasibility and safety study. J Aerosol Med Pulm Drug Deliv 2011; 24 : 261-70.

37 Gagnadoux F, Hureaux J, Vecellio L, Urban T, Le Pape A, Valo I, et al. Aerosolized chemotherapy. J Aerosol Med Pulm Drug Deliv 2008; 21 : 61-70.

38 Labiris NR, Dolovich MB. Pulmonary drug delivery. Part I: physiological factors affecting therapeutic effectiveness of aerosolized medications. Br J Clin Pharmacol 2003; 56: 588-99.

39 Sharma S, White D, Imondi AR, Placke ME, Vail DM, Kris MG. Development of inhalational agents for oncologic use. J Clin Oncol 2001; 19: 1839-47.

40 Hershey AE, Kurzman ID, Forrest LJ, Bohling CA, Stonerook M, Placke ME, et al. Inhalation chemotherapy for macroscopic primary or metastatic lung tumors: proof of principle using dogs with spontaneously occurring tumors as a model. Clin Cancer Res 1999; 5: 2653-9.
41 Koshkina NV, Waldrep JC, Roberts LE, Golunski E, Melton S, Knight V. Paclitaxel liposome aerosol treatment induces inhibition of pulmonary metastases in murine renal carcinoma model. Clin Cancer Res 2001; 7: 3258-62.

42 Zarogoulidis P, Chatzaki E, Porpodis K, Domvri K, Hohenforst-Schmidt W, Goldberg EP, et al. Inhaled chemotherapy in lung cancer: future concept of nanomedicine. Int J Nanomedicine 2012; 7: 1551-72.

43 Gautam A, Koshkina N. Paclitaxel (taxol) and taxoid derivates for lung cancer treatment: potential for aerosol delivery. Curr Cancer Drug Targets 2003; 3: 287-96.

44 Selting K, Waldrep JC, Reinero C, Branson K, Gustafson D, Kim DY, et al. Feasibility and safety of targeted cisplatin delivery to a select lung lobe in dogs via the AeroProbe intracorporeal nebulization catheter. J Aerosol Med Pulm Drug Deliv 2008; 21: 255-68.

45 Deffebach ME, Charan NB, Lakshminarayan S, Butler J. The bronchial circulation. Small, but a vital attribute of the lung. Am Rev Respir Dis 1987; 135: 463-81.

46 Keith RL, Miller YE, Gemmill RM, Drabkin HA, Dempsey EC, Kennedy $\mathrm{TC}$, et al. Angiogenic squamous dysplasia in bronchi of individuals at high risk for lung cancer. Clin Cancer Res 2000; 6: 1616-25.

47 Miller BJ, Rosenbaum AS. The vascular supply to metastatic tumors of the lung. Surg Gynecol Obstet 1967; 125: 1009-12.

48 Milne EN, Noonan CD, Margulis AR, Stoughton JA. Vascular supply of pulmonary metastases. Experimental study in rats. Invest Radiol 1969; 4: 215-29.

49 Khanna C, Anderson PM, Hasz DE, Katsanis E, Neville M, Klausner JS. Interleukin-2 liposome inhalation therapy is safe and effective for dogs with spontaneous pulmonary metastases. Cancer 1997; 79: 1409-21.

50 Guma SR, Lee DA, Ling Y, Gordon N, Kleinerman ES. Aerosol interleukin-2 induces natural killer cell proliferation in the lung and combination therapy improves the survival of mice with osteosarcoma lung metastasis. Pediatr Blood Cancer 2014; 61: 1362-8.

51 Kleinstreuer C, Zhang Z, Donohue JF. Targeted drug-aerosol delivery in the human respiratory system. Annu Rev Biomed Eng 2008; 10: 195-220.

52 Zarogoulidis P, Papanas N, Kouliatsis G, Spyratos D, Zarogoulidis K, Maltezos E. Inhaled insulin: too soon to be forgotten? J Aerosol Med Pulm Drug Deliv 2011; 24: 213-23.

53 Zhang Z, Kleinstreuer C, Kim CS, Hickey AJ. Aerosol transport and deposition in a triple bifurcation bronchial airway model with local tumors. Inhal Toxicol 2002; 14: 1111-33.

54 Kerr DJ, Kaye SB. Aspects of cytotoxic drug penetration, with particular reference to anthracyclines. Cancer Chemother Pharmacol 1987; 19: 1-5.

55 Tunggal JK, Cowan DS, Shaikh H, Tannock IF. Penetration of anticancer drugs through solid tissue: a factor that limits the effectiveness of chemotherapy for solid tumors. Clin Cancer Res 1999; 5: 1583-6.

56 Wartenberg $\mathrm{M}$, Acker $\mathrm{H}$. Induction of cell death by Doxorubicin in multicellular spheroids as studied by confocal laser scanning microscopy. Anticancer Res 1996; 16: 573-9.

57 Durand RE. Chemosensitivity testing in V79 spheroids: drug delivery and cellular microenvironment. J Natl Cancer Inst 1986; 77: $247-$ 52.

58 Nederman T, Carlsson J, Malmqvist M. Penetration of substances into tumor tissue - a methodological study on cellular spheroids. In Vitro 1981; 17: 290-8.

59 Kuh HJ, Jang SH, Wientjes MG, Weaver JR, Au JL. Determinants of paclitaxel penetration and accumulation in human solid tumor. J 
Pharmacol Exp Ther 1999; 290: 871-80.

60 Peer D, Karp JM, Hong S, Farokhzad OC, Margalit R, Langer R. Nanocarriers as an emerging platform for cancer therapy. Nat Nano 2007; 2: 751-60.

61 Brigger I, Dubernet C, Couvreur P. Nanoparticles in cancer therapy and diagnosis. Adv Drug Deliv Rev 2002; 54: 631-51.

62 Ferrari M. Cancer nanotechnology: opportunities and challenges. Nat Rev Cancer 2005; 5: 161-71.

63 Müller RH, Mäder K, Gohla S. Solid lipid nanoparticles (SLN) for controlled drug delivery - a review of the state of the art. Eur J Pharm Biopharm 2000; 50: 161-77.

64 Panyam J, Labhasetwar V. Biodegradable nanoparticles for drug and gene delivery to cells and tissue. Adv Drug Deliv Rev 2003; 55 : 329-47.

65 Farokhzad OC, Langer R. Impact of nanotechnology on drug delivery. ACS Nano 2009; 3: 16-20.

66 Moghimi SM, Hunter AC, Murray JC. Long-circulating and targetspecific nanoparticles: theory to practice. Pharmacol Rev 2001; 53: 283-318.

67 Ghosh P, Han G, De M, Kim CK, Rotello VM. Gold nanoparticles in delivery applications. Adv Drug Deliv Rev 2008; 60: 1307-15.

68 Zhang H, Hollis CP, Zhang Q, Li T. Preparation and antitumor study of camptothecin nanocrystals. Int J Pharm 2011; 415: 293-300.

69 Hollis CP, Weiss HL, Leggas M, Evers BM, Gemeinhart RA, Li T. Biodistribution and bioimaging studies of hybrid paclitaxel nanocrystals: lessons learned of the EPR effect and image-guided drug delivery. J Control Release 2013; 172: 12-21.

70 Hollis CP, Weiss HL, Evers BM, Gemeinhart RA, Li T. In vivo investigation of hybrid paclitaxel nanocrystals with dual fluorescent probes for cancer theranostics. Pharm Res 2014; 31: 1450-9.

71 Roa WH, Azarmi S, Al-Hallak MHDK, Finlay WH, Magliocco AM, Löbenberg R. Inhalable nanoparticles, a non-invasive approach to treat lung cancer in a mouse model. J Control Release 2011; 150: 49-55.

72 Zou Y, Fu H, Ghosh S, Farquhar D, Klostergaard J. Antitumor activity of hydrophilic Paclitaxel copolymer prodrug using locoregional delivery in human orthotopic non-small cell lung cancer xenograft models. Clin Cancer Res 2004; 10: 7382-91.

73 Jyoti K, Kaur K, Pandey RS, Jain UK, Chandra R, Madan J. Inhalable nanostructured lipid particles of 9-bromo-noscapine, a tubulin-binding cytotoxic agent: In vitro and in vivo studies. J Colloid Interface Sci 2015; 445: 219-30.

74 Gill KK, Nazzal S, Kaddoumi A. Paclitaxel loaded PEG(5000)DSPE micelles as pulmonary delivery platform: formulation characterization, tissue distribution, plasma pharmacokinetics, and toxicological evaluation. Eur J Pharm Biopharm 2011; 79: 276-84.

75 Taratula O, Garbuzenko OB, Chen AM, Minko T. Innovative strategy for treatment of lung cancer: targeted nanotechnology-based inhalation co-delivery of anticancer drugs and siRNA. J Drug Target 2011; 19: 900-14.

76 Matsumura Y, Maeda H. A new concept for macromolecular therapeutics in cancer chemotherapy: mechanism of tumoritropic accumulation of proteins and the antitumor agent smancs. Cancer Res 1986; 46: 6387-92.

77 Maeda $\mathrm{H}$. The enhanced permeability and retention (EPR) effect in tumor vasculature: the key role of tumor-selective macromolecular drug targeting. Adv Enzyme Regul 2001; 41: 189-207.

78 Maeda H, Wu J, Sawa T, Matsumura Y, Hori K. Tumor vascular permeability and the EPR effect in macromolecular therapeutics: a review. J Control Release 2000; 65: 271-84.

79 Hobbs SK, Monsky WL, Yuan F, Roberts WG, Griffith L, Torchilin VP, et al. Regulation of transport pathways in tumor vessels: Role of tumor type and microenvironment. Proc Natl Acad Sci U S A 1998; 95 : 4607-12.

80 Minko T, Kopečkova P, Pozharov V, Jensen KD, Kopeček J. The influence of cytotoxicity of macromolecules and of VEGF gene modulated vascular permeability on the enhanced permeability and retention effect in resistant solid tumors. Pharm Res 2000; 17: 505-14.

81 Markman JL, Rekechenetskiy A, Holler E, Ljubimova JY. Nanomedicine therapeutic approaches to overcome cancer drug resistance. Adv Drug Deliv Rev 2013; 65: 1866-79.

82 Patel NR, Pattni BS, Abouzeid AH, Torchilin VP. Nanopreparations to overcome multidrug resistance in cancer. Adv Drug Deliv Rev 2013; 65: $1748-62$.

83 Rosiere R, Van Woensel M, Mathieu V, Langer I, Mathivet T, Vermeersch $\mathrm{M}$, et al. Development and evaluation of well-tolerated and tumor-penetrating polymeric micelle-based dry powders for inhaled anti-cancer chemotherapy. Int J Pharm 2016; 501: 148-59.

84 Tomoda K, Ohkoshi T, Hirota K, Sonavane GS, Nakajima T, Terada $\mathrm{H}$, et al. Preparation and properties of inhalable nanocomposite particles for treatment of lung cancer. Colloids Surf B Biointerfaces 2009; 71: 177-82.

85 Garbuzenko OB, Mainelis G, Taratula O, Minko T. Inhalation treatment of lung cancer: the influence of composition, size and shape of nanocarriers on their lung accumulation and retention. Cancer Biol Med 2014; 11: 44-55.

86 Davis ME, Chen Z, Shin DM. Nanoparticle therapeutics: an emerging treatment modality for cancer. Nat Rev Drug Discov 2008; 7: 77182.

87 Araujo L, Löbenberg R, Kreuter J. Influence of the surfactant concentration on the body distribution of nanoparticles. J Drug Target 1999; 6: 373-85.

88 Hitzman CJ, Wattenberg LW, Wiedmann TS. Pharmacokinetics of 5 -fluorouracil in the hamster following inhalation delivery of lipidcoated nanoparticles. J Pharm Sci 2006; 95: 1196-211.

89 Koshkina NV, Gilbert BE, Waldrep JC, Seryshev A, Knight V. Distribution of camptothecin after delivery as a liposome aerosol or following intramuscular injection in mice. Cancer Chemother Pharmacol 1999; 44: 187-92.

90 Kaminskas LM, McLeod VM, Ryan GM, Kelly BD, Haynes JM, Williamson $\mathrm{M}$, et al. Pulmonary administration of a doxorubicinconjugated dendrimer enhances drug exposure to lung metastases and improves cancer therapy. J Control Release 2014; 183: 18-26.

91 Burnett PE, Barrow RK, Cohen NA, Snyder SH, Sabatini DM. RAFT1 phosphorylation of the translational regulators p70 S6 kinase and 4E-BP1. Proc Natl Acad Sci U S A 1998; 95: 1432-7.

92 Zhu J, Liao L, Zhu L, Zhang P, Guo K, Kong J, et al. Size-dependent cellular uptake efficiency, mechanism, and cytotoxicity of silica nanoparticles toward HeLa cells. Talanta 2013; 107: 408-15.

93 Hafez IM, Cullis PR. Roles of lipid polymorphism in intracellular delivery. Adv Drug Deliv Rev 2001; 47: 139-48.

94 Cevc G, Richardsen H. Lipid vesicles and membrane fusion. Adv Drug Deliv Rev 1999; 38: 207-32.

95 Andresen TL, Jensen SS, Jørgensen K. Advanced strategies in liposomal cancer therapy: Problems and prospects of active and tumor specific drug release. Prog Lipid Res 2005; 44: 68-97.

96 Joshi N, Shirsath N, Singh A, Joshi KS, Banerjee R. Endogenous lung surfactant inspired $\mathrm{pH}$ responsive nanovesicle aerosols: Pulmonary compatible and site-specific drug delivery in lung metastases. Sci Rep 2014; 4: 7085.

97 Leamon CP, Reddy JA. Folate-targeted chemotherapy. Adv Drug Deliv 
Rev 2004; 56: 1127-41.

98 Sudimack J, Lee RJ. Targeted drug delivery via the folate receptor. Adv Drug Deliv Rev 2000; 41: 147-62.

99 Bremer RE, Scoggin TS, Somers EB, O’Shannessy DJ, Tacha DE. Interobserver agreement and assay reproducibility of folate receptor $\alpha$ expression in lung adenocarcinoma: a prognostic marker and potential therapeutic target. Arch Pathol Lab Med 2013; 137: 1747 52.

100 O'Shannessy DJ, Yu G, Smale R, Fu YS, Singhal S, Thiel RP, et al. Folate receptor alpha expression in lung cancer: diagnostic and prognostic significance. Oncotarget 2012; 3: 414-25.

101 Cagle PT, Zhai QJ, Murphy L, Low PS. Folate receptor in adenocarcinoma and squamous cell carcinoma of the lung: potential target for folate-linked therapeutic agents. Arch Pathol Lab Med 2013; 137 : 241-4.

102 Rusch V, Klimstra D, Venkatraman E, Pisters PWT, Langenfeld J, Dmitrovsky E. Overexpression of the epidermal growth factor receptor and its ligand transforming growth factor $\alpha$ is frequent in resectable non-small cell lung cancer but does not predict tumor progression. Clin Cancer Res 1997; 3: 515-22.

103 Dharap SS, Wang Y, Chandna P, Khandare JJ, Qiu B, Gunaseelan S, et al. Tumor-specific targeting of an anticancer drug delivery system by LHRH peptide. Proc Natl Acad Sci U S A 2005; 102: 12962-7.

104 Khandare JJ, Chandna P, Wang Y, Pozharov VP, Minko T. Novel polymeric prodrug with multivalent components for cancer therapy. J Pharmacol Exp Ther 2006; 317: 929-37.

105 Tseng CL, Wang TW, Dong GC, Yueh-Hsiu Wu S, Young TH, Shieh $\mathrm{MJ}$, et al. Development of gelatin nanoparticles with biotinylated EGF conjugation for lung cancer targeting. Biomaterials 2007; 28: 3996-4005.

106 Tseng CL, Wu SY, Wang WH, Peng CL, Lin FH, Lin CC, et al. Targeting efficiency and biodistribution of biotinylated-EGF-conjugated gelatin nanoparticles administered via aerosol delivery in nude mice with lung cancer. Biomaterials 2008; 29: 3014-22.

107 Sadhukha T, Wiedmann TS, Panyam J. Inhalable magnetic nanoparticles for targeted hyperthermia in lung cancer therapy. Biomaterials 2013; 34: 5163-71.

108 Tseng CL, Su WY, Yen KC, Yang KC, Lin FH. The use of biotinylatedEGF-modified gelatin nanoparticle carrier to enhance cisplatin accumulation in cancerous lungs via inhalation. Biomaterials 2009; 30: 3476-85.

109 Taratula O, Kuzmov A, Shah M, Garbuzenko OB, Minko T. Nanostructured lipid carriers as multifunctional nanomedicine platform for pulmonary co-delivery of anticancer drugs and siRNA. J Control Release 2013; 171: 349-57.

110 Jain RK, Stylianopoulos T. Delivering nanomedicine to solid tumors. Nat Rev Clin Oncol 2010; 7: 653-64.

111 Shields Mario A, Dangi-Garimella S, Redig Amanda J, Munshi Hidayatullah G. Biochemical role of the collagen-rich tumour microenvironment in pancreatic cancer progression. Biochem J 2012; 441: 541-52.

112 Sethi T, Rintoul RC, Moore SM, MacKinnon AC, Salter D, Choo C, et al. Extracellular matrix proteins protect small cell lung cancer cells against apoptosis: A mechanism for small cell lung cancer growth and drug resistance in vivo. Nat Med 1999; 5: 662-8.

113 Soto-Pantoja DR, Menon J, Gallagher PE, Tallant EA. Angiotensin-(1-7) inhibits tumor angiogenesis in human lung cancer xenografts with a reduction in vascular endothelial growth factor. Mol Cancer Ther 2009; 8: 1676-83.

114 Cabral H, Matsumoto Y, Mizuno K, Chen Q, Murakami M, Kimura $\mathrm{M}$, et al. Accumulation of sub-100 $\mathrm{nm}$ polymeric micelles in poorly permeable tumours depends on size. Nat Nanotechnol 2011; 6: 815-23.

115 Diop-Frimpong B, Chauhan VP, Krane S, Boucher Y, Jain RK. Losartan inhibits collagen I synthesis and improves the distribution and efficacy of nanotherapeutics in tumors. Proc Natl Acad Sci U S A 2011; 108: 2909-14.

116 Chauhan VP, Popović Z, Chen O, Cui J, Fukumura D, Bawendi MG, et al. Fluorescent nanorods and nanospheres for real-time in vivo probing of nanoparticle shape-dependent tumor penetration. Angew Chem Int Ed Engl 2011; 50: 11417-20.

117 Mckee TD, Grandi P, Mok W, Alexandrakis G, Insin N, Zimmer JP, et al. Degradation of fibrillar collagen in a human melanoma xenograft improves the efficacy of an oncolytic herpes simplex virus vector. Cancer Res 2006; 66: 2509-13.

118 Liu J, Liao S, Diop-Frimpong B, Chen W, Goel S, Naxerova K, et al. TGF-beta blockade improves the distribution and efficacy of therapeutics in breast carcinoma by normalizing the tumor stroma. Proc Natl Acad Sci U S A 2012; 109: 16618-23.

119 Godugu C, Patel AR, Doddapaneni R, Marepally S, Jackson T, Singh M. Inhalation delivery of telmisartan enhances intratumoral distribution of nanoparticles in lung cancer models. J Control Release 2013; 172: 86-95.

120 Hussain S, Pluckthun A, Allen TM, Zangemeister-Wittke U. Antitumor activity of an epithelial cell adhesion molecule targeted nanovesicular drug delivery system. Mol Cancer Ther 2007; 6: 3019-27.

121 Kobayashi T, Ishida T, Okada Y, Ise S, Harashima H, Kiwada H. Effect of transferrin receptor-targeted liposomal doxorubicin in P-glycoprotein-mediated drug resistant tumor cells. Int J Pharm 2007; 329: 94-102.

122 Lopes De Menezes DE, Pilarski LM, Allen TM. In vitro and in vivo targeting of immunoliposomal doxorubicin to human B-cell lymphoma. Cancer Res 1998; 58: 3320-30.

123 Koopaei MN, Dinarvand R, Amini M, Rabbani H, Emami S, Ostad SN, et al. Docetaxel immunonanocarriers as targeted delivery systems for HER 2-positive tumor cells: preparation, characterization, and cytotoxicity studies. Int J Nanomedicine 2011; 6: 1903-12.

124 Choi SH, Byeon HJ, Choi JS, Thao L, Kim I, Lee ES, et al. Inhalable self-assembled albumin nanoparticles for treating drug-resistant lung cancer. J Control Release 2015; 197: 199-207.

$125 \mathrm{Hu}$ L, Jia Y, WenDing. Preparation and characterization of solid lipid nanoparticles loaded with epirubicin for pulmonary delivery. Pharmazie 2010; 65: 585-7.

126 Wittgen BP, Kunst PW, van der Born K, van Wijk AW, Perkins W, Pilkiewicz FG, et al. Phase I study of aerosolized SLIT cisplatin in the treatment of patients with carcinoma of the lung. Clin Cancer Res 2007; 13: 2414-21.

127 Verschraegen CF, Gilbert BE, Loyer E, Huaringa A, Walsh G, Newman RA, et al. Clinical evaluation of the delivery and safety of aerosolized liposomal 9-nitro-20(s)-camptothecin in patients with advanced pulmonary malignancies. Clin Cancer Res 2004; 10: 2319-26.

128 Minko T, Dharap SS, Pakunlu RI, Wang Y. Molecular targeting of drug delivery systems to cancer. Curr Drug Targets 2004; 5: 389-406.

129 Dong X, Mumper RJ. Nanomedicinal strategies to treat multidrugresistant tumors: current progress. Nanomedicine (Lond) 2010; 5: 597-615.

130 Gross A, McDonnell JM, Korsmeyer SJ. BCL-2 family members and the mitochondria in apoptosis. Genes Dev 1999; 13: 1899-911.

131 Reed JC. Dysregulation of apoptosis in cancer. J Clin Oncol 1999; 17: 2941.

132 Garbuzenko OB, Saad M, Pozharov VP, Reuhl KR, Mainelis G, Minko T. Inhibition of lung tumor growth by complex pulmonary delivery of 
drugs with oligonucleotides as suppressors of cellular resistance. Proc Natl Acad Sci U S A 2010; 107: 10737-42.

133 Pakunlu RI, Cook TJ, Minko T. Simultaneous modulation of multidrug resistance and antiapoptotic cellular defense by MDR1 and BCL-2 targeted antisense oligonucleotides enhances the anticancer efficacy of doxorubicin. Pharm Res 2003; 20: 351-9.

134 Zhang J, Wu L, Chan HK, Watanabe W. Formation, characterization, and fate of inhaled drug nanoparticles. Adv Drug Deliv Rev 2011; 6: 441-55.

135 Todoroff J, Vanbever R. Fate of nanomedicines in the lungs. Curr Opin Colloid Interface Sci 2011; 16: 246-54.

136 Heyder J. Deposition of inhaled particles in the human respiratory tract and consequences for regional targeting in respiratory drug delivery. Proc Am Thorac Soc 2004; 1: 315-20.

137 Yeh HC, Phalen RF, Raabe OG. Factors influencing the deposition of inhaled particles. Environ Health Perspect 1976; 15: 147-56.

138 Lin YW, Wong J, Qu L, Chan HK, Zhou QT. Powder production and particle engineering for dry powder inhaler formulations. Curr Pharm Des 2015; 21: 3902-16.

139 Telko M, Hickey A. Dry powder inhaler formulation. Respir Care 2005; 50: 1209-27.

140 Martonen TB, Katz IM. Deposition patterns of aerosolized drugs within human lungs: effects of ventilatory parameters. Pharm Res 1993; 10: 871-8.

141 Davies CN, Muir DC. Deposition of inhaled particles in human lungs. Nature 1966; 211: 90-1.

142 Stahlhofen W, Gebhart J, Heyder J. Biological variability of regional deposition of aerosol particles in the human respiratory tract. Am Ind Hyg Assoc J 1981; 42: 348-52.

143 Yeh HC, Schum GM. Models of human lung airways and their application to inhaled particle deposition. Bull Math Biol 1980; 42: 461-80.

144 Sturm R, Hofmann W. A theoretical approach to the deposition and clearance of fibers with variable size in the human respiratory tract. J Hazard Mater 2009; 170: 210-8.

145 Heyder J, Gebhart J, Rudolf G, Schiller CF, Stahlhofen W. Deposition of particles in the human respiratory tract in the size range $0.005-15$ $\mu \mathrm{m}$. J Aerosol Sci 1986; 17: 811-25.

146 Heyder J, Rudolf G. Mathematical models of particle deposition in the human respiratory tract. J Aerosol Sci 1984; 15: 697-707.

147 Byron PR. Prediction of drug residence times in regions of the human respiratory tract following aerosol inhalation. J Pharm Sci 1986; 75: 433-8.

148 Jaques PA, Kim CS. Measurement of total lung deposition of inhaled ultrafine particles in healthy men and women. Inhal Toxicol 2000; 12: $715-31$.

149 Chalupa DC, Morrow PE, Oberdörster G, Utell MJ, Frampton MW. Ultrafine particle deposition in subjects with asthma. Environ Health Perspect 2004; 112: 879-82.

150 Stuart BO. Deposition and clearance of inhaled particles. Environ Health Perspect 1984; 55: 369-90.

151 Möller W, Häussinger K, Winkler-Heil R, Stahlhofen W, Meyer T, Hofmann $W$, et al. Mucociliary and long-term particle clearance in the airways of healthy nonsmoker subjects. J Appl Physiol 2004; 97: 2200-6.

152 Kreyling WG, Semmler-Behnke M, Möller W. Ultrafine particle-lung interactions: does size matter? J Aerosol Med 2006; 19: 74-83.

153 Schmid O, Möller W, Semmler-Behnke M, A. Ferron G, Karg E, Lipka $\mathrm{J}$, et al. Dosimetry and toxicology of inhaled ultrafine particles. Biomarkers 2009; 14: 67-73.

154 Möller W, Felten K, Sommerer K, Scheuch G, Meyer G, Meyer P, et al.
Deposition, retention, and translocation of ultrafine particles from the central airways and lung periphery. Am J Respir Crit Care Med 2008; 177: 426-32.

155 Bur M, Henning A, Hein S, Schneider M, Lehr C-M. Inhalative nanomedicine - opportunities and challenges. Inhal Toxicol 2009; 21: 137-43.

156 Geiser M, Schürch S, Gehr P. Influence of surface chemistry and topography of particles on their immersion into the lung's surfacelining layer. J Appl Physiol 2003; 94: 1793-801.

157 Arredouani M, Yang Z, Ning Y, Qin G, Soininen R, Tryggvason K, et al. The scavenger receptor MARCO is required for lung defense against pneumococcal pneumonia and inhaled particles. J Exp Med 2004; 200: $267-72$.

158 Gumbleton M. Caveolae as potential macromolecule trafficking compartments within alveolar epithelium. Adv Drug Deliv Rev 2001; 49: 281-300.

159 Brain JD. Mechanisms, measurement, and significance of lung macrophage function. Environ Health Perspect 1992; 97: 5-10.

160 Palecanda A, Kobzik L. Receptors for unopsonized particles: The role of alveolar macrophage scavenger receptors. Curr Mol Med 2001; 1 : 589-95.

161 Oberdörster G. Biokinetics and effects of nanoparticles. In: Simeonova PP, Opopol N, Luster MI editors. Nanotechnology toxicological issues and environmental safety and environmental safety. Dordrecht: Springer Netherlands; 2007. p 15-51.

162 Lippmann M, Yeates DB, Albert RE. Deposition, retention, and clearance of inhaled particles. Br J Ind Med 1980; 37: 337-62.

163 Schlesinger RB. Defense mechanisms of the respiratory system. Bioscience 1982; 32: 45-50.

164 Langenback EG, Bergofsky EH, Halpern JG, Foster WM. Supramicronsized particle clearance from alveoli: route and kinetics. J Appl Physiol 1990; 69: 1302-08.

165 Geiser M. Morphological aspects of particle uptake by lung phagocytes. Microsc Res Tech 2002; 57: 512-22.

166 Ferin J. Pulmonary alveolar pores and alveolar macrophagemediated particle clearance. Anat Rec 1982; 203: 265-72.

167 Tabata Y, Ikada Y. Macrophage phagocytosis of biodegradable microspheres composed of L-lactic acid/glycolic acid homo- and copolymers. J Biomed Mater Res 1988; 22: 837-58.

168 Rudt S, Wesemeyer H, Müller RH. In vitro phagocytosis assay of nano- and microparticles by chemiluminescence. IV. Effect of surface modification by coating of particles with poloxamine and Antarox CO on the phagocytic uptake. J Control Release 1993; 25: 123-32.

169 Rudt S, Müller RH. In vitro phagocytosis assay of nano- and microparticles by chemiluminescence. I. Effect of analytical parameters, particle size and particle concentration. J Control Release 1992; 22: 263-71.

170 Kawaguchi H, Koiwai N, Ohtsuka Y, Miyamoto M, Sasakawa S. Phagocytosis of latex particles by leucocytes. I. Dependence of phagocytosis on the size and surface potential of particles. Biomaterials 1986; 7: 61-6.

171 Borm P, Klaessig FC, Landry TD, Moudgil B, Pauluhn J, Thomas K, et al. Research strategies for safety evaluation of nanomaterials, part V: role of dissolution in biological fate and effects of nanoscale particles. Toxicol Sci 2006; 90: 23-32.

172 Madl AK, Pinkerton KE. Health effects of inhaled engineered and incidental nanoparticles. Crit Rev Toxicol 2009; 39: 629-58.

173 Newman SP, Pavia D, Garland N, Clarke SW. Effects of various inhalation modes on the deposition of radioactive pressurized aerosols. Eur J Respir Dis 1982; 63: 57-65. 
174 Patton JS, Byron PR. Inhaling medicines: delivering drugs to the body through the lungs. Nat Rev Drug Discov 2007; 6: 67-74.

175 Rabinow BE. Nanosuspensions in drug delivery. Nat Rev Drug Discov 2004; 3: 785-96.

176 Desai N. Challenges in development of nanoparticle-based therapeutics. AAPS J 2012; 14: 282-95.

177 Hock SC, Ying YM, Wah CL. A review of the current scientific and regulatory status of nanomedicines and the challenges ahead. PDA J Pharm Sci Technol 2011; 65: 177-95.

178 Kalantarian P, Najafabadi AR, Haririan I, Vatanara A, Yamini Y, Darabi $\mathrm{M}$, et al. Preparation of 5-fluorouracil nanoparticles by supercritical antisolvents for pulmonary delivery. Int J Nanomedicine 2010; 5: 763-70.

179 Rogueda PGA, Traini D. The nanoscale in pulmonary delivery. Part 2: formulation platforms. Expert Opin Drug Deliv 2007; 4: 607-20.

180 Zhou Q, Tang P, Leung SSY, Chan JGY, Chan H-K. Emerging inhalation aerosol devices and strategies: where are we headed? Adv Drug Deliv Rev 2014; 75: 3-17.

181 Hureaux J, Lagarce F, Gagnadoux F, Vecellio L, Clavreul A, Roger E, et al. Lipid nanocapsules: ready-to-use nanovectors for the aerosol delivery of paclitaxel. Eur J Pharm Biopharm 2009; 73: 239-46.

182 Mainelis G, Seshadri S, Garbuzenko OB, Han T, Wang Z, Minko T. Characterization and application of a nose-only exposure chamber for inhalation delivery of liposomal drugs and nucleic acids to mice. J Aerosol Med Pulm Drug Deliv 2013; 26: 345-54.

183 Labiris NR, Dolovich MB. Pulmonary drug delivery. Part II: the role of inhalant delivery devices and drug formulations in therapeutic effectiveness of aerosolized medications. Br J Clin Pharmacol 2003; 56: 600-12.

184 Yeo LY, Friend JR, Mclntosh MP, Meeusen ENT, Morton DAV. Ultrasonic nebulization platforms for pulmonary drug delivery. Expert Opin Drug Deliv 2010; 7: 663-79.

185 Xiao W, Oreoluwa OA, Heidi MM. Pulmonary and nasal anti-inflammatory and anti-allergy inhalation aerosol delivery systems. Antiinflamm Antiallergy Agents Med Chem 2011; 10: 215-29.

186 Chan JGY, Wong J, Zhou QT, Leung SSY, Chan H-K. Advances in device and formulation technologies for pulmonary drug delivery. AAPS PharmSciTech 2014; 15: 882-97.

187 Conti DS, Brewer D, Grashik J, Avasarala S, da Rocha SR. Poly(amidoamine) dendrimer nanocarriers and their aerosol formulations for siRNA delivery to the lung epithelium. Mol Pharm 2014; 11 : 1808-22.

188 Newman SP. Therapeutic inhalation agents and devices. Effectiveness in asthma and bronchitis. Postgrad Med 1984; 76: 194203.

189 Bennett WD, Smaldone GC. Human variation in the peripheral airspace deposition of inhaled particles. J Appl Physiol 1987; 62: 1603-10.

190 Crompton GK. Problems patients have using pressurized aerosol inhalers. Eur J Respir Dis Suppl 1982; 119: 101-4.

191 Newman SP, Pavia D, Moren F, Sheahan NF, Clarke SW. Deposition of pressurised aerosols in the human respiratory tract. Thorax 1981; 36: 52-5.

192 Chacón M, Molpeceres J, Berges L, Guzmán M, Aberturas MR. Stability and freeze-drying of cyclosporine loaded poly(d,I lactideglycolide) carriers. Eur J Pharm Sci 1999; 8: 99-107.

193 Abdelwahed W, Degobert G, Stainmesse S, Fessi H. Freeze-drying of nanoparticles: formulation, process and storage considerations. Adv Drug Deliv Rev 2006; 58: 1688-713.

194 Schulze D. Powders and bulk solids: behavior, characterization, storage and flow. Springer; 2008.
195 Zhou QT, Armstrong B, Larson I, Stewart PJ, Morton DAV. Understanding the influence of powder flowability, fluidization and de-agglomeration characteristics on the aerosolization of pharmaceutical model powders. Eur J Pharm Sci 2010; 40: 412-21.

196 Saint-Lorant G, Leterme P, Gayot A, Flament MP. Influence of carrier on the performance of dry powder inhalers. Int J Pharm 2007; 334: 85-91.

197 Hersey JA. Powder mixing: theory and practice in pharmacy. Powder Technol 1976; 15: 149-53.

198 Hersey JA. Ordered mixing: a new concept in powder mixing practice. Powder Technol 1975; 11: 41-4.

199 Floris G, Niels G, Paul H, Henderik Willem F, Anne Haaije de B. Recent advances in the fundamental understanding of adhesive mixtures for inhalation. Curr Pharm Des 2015; 21: 5900-14.

200 Grasmeijer F, Hagedoorn P, Frijlink HW, de Boer HA. Mixing time effects on the dispersion performance of adhesive mixtures for inhalation. PLoS One 2013; 8: e69263.

201 Bohr A, Water J, Beck-Broichsitter M, Yang M. Nanoembedded microparticles for stabilization and delivery of drug-loaded nanoparticles. Curr Pharm Des 2015; 21: 5829-44.

202 Yamasaki K, Kwok PCL, Fukushige K, Prud'homme RK, Chan HK. Enhanced dissolution of inhalable cyclosporine nano-matrix particles with mannitol as matrix former. Int J Pharm 2011; 420: 34-42.

203 Kwok PCL, Tunsirikongkon A, Glover W, Chan HK. Formation of protein nano-matrix particles with controlled surface architecture for respiratory drug delivery. Pharm Res 2011; 28: 788-96.

204 Azarmi S, Tao X, Chen H, Wang Z, Finlay WH, Lobenberg R, et al. Formulation and cytotoxicity of doxorubicin nanoparticles carried by dry powder aerosol particles. Int J Pharm 2006; 319: 155-61.

205 Rosiere R, Gelbcke M, Mathieu V, Van Antwerpen P, Amighi K, Wauthoz N. New dry powders for inhalation containing temozolomide-based nanomicelles for improved lung cancer therapy. Int J Oncol 2015; 47: 1131-42.

206 Mangal S, Meiser F, Tan G, Gengenbach T, Denman J, Rowles MR, et al. Relationship between surface concentration of $L$-leucine and bulk powder properties in spray dried formulations. Eur J Pharm Biopharm 2015; 94: 160-9.

207 Staniforth JN, Morton DAV. Magnesium stearate, a phospholipid, or an amino acid in preparation of pharmaceutical particles for inhalation WO 02/43700. 2002.

208 El-Gendy N, Berkland C. Combination chemotherapeutic dry powder aerosols via controlled nanoparticle agglomeration. Pharm Res 2009; 26: 1752-63.

209 Varshosaz J, Hassanzadeh F, Mardani A, Rostami M. Feasibility of haloperidol-anchored albumin nanoparticles loaded with doxorubicin as dry powder inhaler for pulmonary delivery. Pharm Dev Technol 2015; 20: 183-96.

210 Ely L, Roa W, Finlay WH, Löbenberg R. Effervescent dry powder for respiratory drug delivery. Eur J Pharm Biopharm 2007; 65: 346-53.

211 Azarmi S, Löbenberg R, Roa WH, Tai S, Finlay WH. Formulation and in vivo evaluation of effervescent inhalable carrier particles for pulmonary delivery of nanoparticles. Drug Dev Ind Pharm 2008; 34 : 943-7.

212 Al-Hallak MH, Sarfraz MK, Azarmi S, Roa WH, Finlay WH, Rouleau $C$, et al. Distribution of effervescent inhalable nanoparticles after pulmonary delivery: an in vivo study. Ther Deliv 2012; 3: 725-34.

213 Gupta AK, Gupta M. Synthesis and surface engineering of iron oxide nanoparticles for biomedical applications. Biomaterials 2005; 26 : 3995-4021.

214 Martin AR, Finlay WH. Enhanced deposition of high aspect ratio aerosols in small airway bifurcations using magnetic field alignment. 
J Aerosol Sci 2008; 39: 679-90.

215 Amirfazli A. Nanomedicine: magnetic nanoparticles hit the target. Nat Nanotechnol 2007; 2: 467-8.

216 Douziech-Eyrolles L, Marchais H, Herve K, Munnier E, Souce M, Linassier $C$, et al. Nanovectors for anticancer agents based on superparamagnetic iron oxide nanoparticles. Int J Nanomedicine 2007; 2: 541-50.

217 Veiseh O, Gunn JW, Zhang M. Design and fabrication of magnetic nanoparticles for targeted drug delivery and imaging. Adv Drug Deliv Rev 2010; 62: 284-304.

218 Dames P, Gleich B, Flemmer A, Hajek K, Seidl N, Wiekhorst F, et al. Targeted delivery of magnetic aerosol droplets to the lung. Nat Nanotechnol 2007; 2: 495-9.

219 Hasenpusch G, Geiger J, Wagner K, Mykhaylyk O, Wiekhorst F, Trahms $L$, et al. Magnetized aerosols comprising superparamagnetic iron oxide nanoparticles improve targeted drug and gene delivery to the lung. Pharm Res 2012; 29: 1308-18.

220 Xie Y, Zeng P, Siegel RA, Wiedmann TS, Hammer BE, Longest PW. Magnetic deposition of aerosols composed of aggregated superparamagnetic nanoparticles. Pharm Res 2010; 27: 855-65.

221 Xie Y, Longest PW, Xu YH, Wang JP, Wiedmann TS. In vitro and in vivo lung deposition of coated magnetic aerosol particles. J Pharm Sci 2010; 99: 4658-68.

222 McBride AA, Price DN, Lamoureux LR, Elmaoued AA, Vargas JM, Adolphi NL, et al. Preparation and characterization of novel magnetic nano-in-microparticles for site-specific pulmonary drug delivery. Mol Pharm 2013; 10: 3574-81.

223 Verma NK, Crosbie-Staunton K, Satti A, Gallagher S, Ryan KB, Doody $\mathrm{T}$, et al. Magnetic core-shell nanoparticles for drug delivery by nebulization. J Nanobiotechnol 2013; 11: 1-12.

224 Hadinoto K, Phanapavudhikul P, Kewu Z, Tan RBH. Dry powder aerosol delivery of large hollow nanoparticulate aggregates as prospective carriers of nanoparticulate drugs: effects of phospholipids. Int J Pharm 2007; 333: 187-98.

225 Tsapis N, Bennett D, Jackson B, Weitz DA, Edwards DA. Trojan particles: large porous carriers of nanoparticles for drug delivery. Proc Natl Acad Sci U S A 2002; 99: 12001-5.

226 Vonarbourg A, Passirani C, Saulnier P, Simard P, Leroux JC, Benoit JP. Evaluation of pegylated lipid nanocapsules versus complement system activation and macrophage uptake. J Biomed Materials Res Part A 2006; 78A: 620-8.

227 Edwards DA, Ben-Jebria A, Langer R. Recent advances in pulmonary drug delivery using large, porous inhaled particles. J Appl Physiol 1998; 85: 379-85.

228 Edwards DA, Hanes J, Caponetti G, Hrkach J, Ben-Jebria A, Eskew ML, et al. Large porous particles for pulmonary drug delivery. Science 1997; 276: 1868-72.

229 Sung JC, Pulliam BL, Edwards DA. Nanoparticles for drug delivery to the lungs. Trends Biotechnol 2007; 25: 563-70.

230 Vanbever R, Mintzes JD, Wang J, Nice J, Chen D, Batycky R, et al. Formulation and physical characterization of large porous particles for inhalation. Pharm Res 1999; 16: 1735-42.

231 Steckel H, Brandes HG. A novel spray-drying technique to produce
Iow density particles for pulmonary delivery. Int J Pharm 2004; 278 : 187-95.

232 Dellamary LA, Tarara TE, Smith DJ, Woelk CH, Adractas A, Costello $\mathrm{ML}$, et al. Hollow porous particles in metered dose inhalers. Pharm Res 2000; 17: 168-74.

233 Hadinoto K, Zhu K, Tan RB. Drug release study of large hollow nanoparticulate aggregates carrier particles for pulmonary delivery. Int J Pharm 2007; 341: 195-206.

234 El-Sherbiny IM, McGill S, Smyth HD. Swellable microparticles as carriers for sustained pulmonary drug delivery. J Pharm Sci 2010; 99: 2343-56.

235 El-Sherbiny IM, Smyth HD. Biodegradable nano-micro carrier systems for sustained pulmonary drug delivery: (I) self-assembled nanoparticles encapsulated in respirable/swellable semi-IPN microspheres. Int J Pharm 2010; 395: 132-41.

236 Koussoroplis SJ, Paulissen G, Tyteca D, Goldansaz H, Todoroff J, Barilly $\mathrm{C}$, et al. PEGylation of antibody fragments greatly increases their local residence time following delivery to the respiratory tract. J Control Release 2014; 187: 91-100.

237 Lai SK, O'Hanlon DE, Harrold S, Man ST, Wang YY, Cone R, et al. Rapid transport of large polymeric nanoparticles in fresh undiluted human mucus. Proc Natl Acad Sci U S A 2007; 104: 1482-7.

238 Thorley AJ, Tetley TD. New perspectives in nanomedicine. Pharmacol Ther 2013; 140: 176-85.

239 Youn YS, Kwon MJ, Na DH, Chae SY, Lee S, Lee KC. Improved intrapulmonary delivery of site-specific PEGylated salmon calcitonin: optimization by PEG size selection. J Control Release 2008; 125 : 68-75.

240 Luo T, Loira-Pastoriza C, Patil HP, Ucakar B, Muccioli GG, Bosquillon $\mathrm{C}$, et al. PEGylation of paclitaxel largely improves its safety and antitumor efficacy following pulmonary delivery in a mouse model of lung carcinoma. J Control Release 2016; 239: 62-71.

241 Evora C, Soriano I, Rogers RA, Shakesheff KM, Hanes J, Langer R. Relating the phagocytosis of microparticles by alveolar macrophages to surface chemistry: the effect of 1,2-dipalmitoylphosphatidylcholine. J Control Release 1998; 51: 143-52.

242 Jones BG, Dickinson PA, Gumbleton M, Kellaway IW. Lung surfactant phospholipids inhibit the uptake of respirable microspheres by the alveolar macrophage NR8383. J Pharm Pharmacol 2002; 54: 1065-72.

243 Meenach SA, Vogt FG, Anderson KW, Hilt JZ, McGarry RC, Mansour HM. Design, physicochemical characterization, and optimization of organic solution advanced spray-dried inhalable dipalmitoylphosphatidylcholine (DPPC) and dipalmitoylphosphatidylethanolami ne poly(ethylene glycol) (DPPE-PEG) microparticles and nanoparticles for targeted respiratory nanomedicine delivery as dry powder inhalation aerosols. Int J Nanomed 2013; 8: 275-93.

244 Meenach SA, Anderson KW, Hilt JZ, McGarry RC, Mansour HM. High-performing dry powder inhalers of paclitaxel DPPC/DPPG lung surfactant-mimic multifunctional particles in lung cancer: physicochemical characterization, in vitro aerosol dispersion, and cellular studies. AAPS PharmSciTech 2014; 15: 1574-87. 